\title{
Harnessing regulatory T cell neuroprotective activities for treatment of neurodegenerative disorders
}

\author{
Jatin Machhi', Bhavesh D. Kevadiya ${ }^{1,2}$, ljaz Khan Muhammad ${ }^{1,3}$, Jonathan Herskovitz ${ }^{1,4}$, Katherine E. Olson, \\ R. Lee Mosley ${ }^{1}$ and Howard E. Gendelman ${ }^{1,4^{*}}$ (D)
}

\begin{abstract}
Emerging evidence demonstrates that adaptive immunity influences the pathobiology of neurodegenerative disorders. Misfolded aggregated self-proteins can break immune tolerance leading to the induction of autoreactive effector T cells (Teffs) with associated decreases in anti-inflammatory neuroprotective regulatory T cells (Tregs). An imbalance between Teffs and Tregs leads to microglial activation, inflammation and neuronal injury. The cascade of such a disordered immunity includes the drainage of the aggregated protein antigens into cervical lymph nodes serving to amplify effector immune responses. Both preclinical and clinical studies demonstrate transformation of this altered immunity for therapeutic gain. We posit that the signs and symptoms of common neurodegenerative disorders such as Alzheimer's and Parkinson's diseases, amyotrophic lateral sclerosis, and stroke can be attenuated by boosting Treg activities.
\end{abstract}

Keywords: Regulatory T cells (Tregs), Effector T cells (Teffs), Dendritic cells, Microglia, Immune transformation, Neurodegenerative disorders

\section{Highlights}

- Misfolded self-proteins can break immune tolerance.

- Dominant effector T cell responses can affect disease onset and progression.

- Effector T cells can exacerbate microglial inflammation.

- Regulatory T cells suppress adaptive and innate effectors.

- Boosting regulatory $\mathrm{T}$ cell frequency and function serve as a neuroprotective role.

\footnotetext{
* Correspondence: hegendel@unmc.edu

'Department of Pharmacology and Experimental Neuroscience, Center for Neurodegenerative Disorders, University of Nebraska Medical Center, Omaha, NE 68198-5880, USA

${ }^{4}$ Department of Pathology and Microbiology, University of Nebraska Medical Center, Omaha, NE 68198-5880, USA

Full list of author information is available at the end of the article
}

\section{Background}

As of now, only symptomatic therapies are available to abate the signs and symptoms of neurodegenerative disorders. This lack of disease-combating neurorestorative agents has promoted research efforts into finding the means to attenuate disease. One of these therapies builds on the correction of peripheral-brain immune asymmetry through harnessing the powers of adaptive immunity [1-3]. For decades disease mitigating immune responses were studied for their abilities to find then eliminate infectious and cancerous threats. However, what was not known, until the recent decade, was that they can also affect the pathobiology of central nervous system (CNS) disease. The loss of CNS immune privilege has forged new investigations into the ways neurodegenerative disorders can be treated [3-5]. Indeed, it is now accepted that adaptive immunity can affect brain development and homeostasis. For example, deficiencies in 
$\mathrm{CD} 4+\mathrm{T}$ cell number and function lead to impaired neurogenesis and cognition [6, 7]. Also, restoring a balance between divergent $T$ cell subsets can sustain neuronal homeostasis and preclude disease-inciting proinflammatory events [2, 8]. Progressive neurodegenerative, neuroinflammatory, and neuroinfectious disease rests, in measure, around adaptive immunity. All are sped by elevated effector and downregulated regulatory T cells (Teffs and Tregs) [5, 9]. However, past attempts to correct such aberrant host immunity using immunosuppressive agents have failed to affect disease outcomes $[10,11]$. This led to initial discouragements in immunebased approaches for CNS disease by some neuroimmunologists. Indeed, by some due diligence, a new therapeutic frontier has emerged designed to transform neurotoxic Teffs into neuroprotective Tregs. This led to the idea that the microenvironment of the diseased brain could be altered through the control of disease-inciting neuroinflammation. A new created microenvironment was made that served to slow or even prevent disease progression $[2,12]$. The idea was restoring disease altered CNS immune homeostasis. This was accomplished by breaking the chain link between systemic neuroinflammation and neural injury $[4,5]$ through immune transformation.

All together, CNS disorders are intertwined with basic immune processes of antigen presentation, cytokine secretion, leukocyte recruitment, cell activation, macromolecular lymphatic drainage, and inflammation. How immunity and CNS disease are linked remained a black box in trying to explain the notion of both detrimental and restorative immunity. It was found that the control of specific $\mathrm{T}$ cell functional phenotypes affect disease control $[3-5,13,14]$. While adaptive immunity has broad biologic and physiological consequences to the nervous system $[2,9,15]$ how it can be tamed in developing therapeutic strategies proved key in establishing a bridge between $\mathrm{T}$ cell function and brain repair. This proved complex as it is based on the brain's ever changing microenvironment and the evolution of immune functions $[10,11]$.

What is now broadly accepted is that activation of peripheral immunity, regardless of cause, triggers neural tissue repair and controls the tempo of CNS injury $[1,2,5$, $16]$. Both innate and adaptive immunity can incite neuroinflammation and accelerate aggregated misfolded protein accumulation that lead to neuronal demise. Such pathogenic events are operative, at varying degrees, in Alzheimer's and Parkinson's diseases (AD and PD), amyotrophic lateral sclerosis (ALS), multiple sclerosis (MS), and stroke $[1,3,12,17-21]$. In contrast, peripheral immunity also facilitates brain repair [2, 3, 9], in part, by suppression of neurotoxic Teff responses [1, 22-26]. Therapeutic immune transformers include, but are not limited to, glatiramer acetate, anti-CD3, rapamycin, granulocytemacrophage colony stimulating factor (GM-CSF), histone deacetylase inhibitors (HDACi), vasoactive intestinal peptide (VIP), VIP receptor-2 agonist, interleukin-2 (IL-2), and snake and bee venoms [1,22, 24-30]. All induce substantive neuroprotective Tregs. To these ends, we review how Tregs serve to sustain brain homeostasis in variant neurodegenerative conditions.

\section{CNS immunity and $\mathrm{T}$ cells}

Peripheral immunocytes [ $\mathrm{T}$ cells, B cells, natural killer (NK) cells, and dendritic cells (DCs)] are present in the brain parenchyma, the meninges, and the choroid plexus. There they can serve as either neuroprotectants or disease instigators depending upon the local environment $[4,5]$. CD4+ to CD8+ cells patrol the cerebrospinal fluid (CSF) in search of cognate antigen and upon recognition induce local memory effector immune responses [31, 32]. Also, antigen-presenting cells (APCs) macrophages, and DCs distributed in meningeal, choroid plexus, and perivascular compartments, work in tandem, to affect $\mathrm{T}$ cell neuroimmunity $[4,33]$. While searching for cognate antigen, $\mathrm{T}$ cell interactions with innate microglia and astrocytes also affect CNS homeostasis. In the absence of antigen recognition and activation, $\mathrm{T}$ cells return to the periphery through the CNS lymphatic draining system into the deep cervical lymph nodes. In the healthy brain, entry and exit of circulating immunocytes are greatly controlled to maintain homeostatic neuronal function. However, during inflammation (Fig. 2), immunocytes and CNS antigens interactions in secondary lymph nodes affect the bloodbrain-barrier (BBB, composed of astrocytic end feet and parenchymal basal lamina) cell trafficking and secretory activities [4]. Leakiness in the BBB and blood-CSF barriers leads to altered transporter and cytokine responses that allow excessive transmigration of immune cells into the brain with secondary pro-inflammatory activities $[5,9,11,34]$. While antigen-specific CD4+ $\mathrm{T}$ cells cross the BBB [35], it is their antigen recognition that induces immune responses known to affect the upregulation of trafficking molecules, cell transmigration, and neural integrity [4]. When $\mathrm{T}$ cells do not recognize cognate antigen, they do not cross the BBB and undergo apoptosis [36]. $\mathrm{T}$ cells constantly patrol for cognate antigen in the CNS draining lymph nodes. Peripheral $\mathrm{T}$ cell effects on brain pathology are notable as removal of their draining lymph nodes significantly affects disease severity [37]. Even without crossing the BBB, T cells maintain brain function through a cascade of immune signaling and secreted molecules [38-40]. Therefore, the coordinated immune responses, in and outside the $\mathrm{CNS}$, have broad functional consequences to the brain. 
The notion that immune cells and macromolecules have limited access inside the CNS is no longer believed [41, 42]. Recent studies re-identified prior works demonstrating a structural and functional glymphatic system serving to control waste management $[14,43,44]$. The passing of CSF from the subarachnoid space through the arterial paravascular space to the brain interstitium collects cellular waste through the aquaporin water channel. The resulting CSF flow moves toward the venous perivascular space and brings waste into the meningeal lymphatic vessels where it drains into secondary lymphoid tissue [4346]. This glymphatic system facilitates brain clearance of both hydrophilic and lipophilic compounds and is pivotal in the removal of neurotoxic protein aggregates like amyloid-beta $(\mathrm{A} \beta)$. When the glymphatic system becomes dysfunctional, it plays a key role in AD pathobiology [47]. Cellular macromolecules also leave the CNS by CSF drainage from the cribriform plate into nasal lymphatic vasculature. These enter the subarachnoid space to reach the meningeal lymphatics that deliver materials to deep cervical lymph nodes [4]. Both cellular waste-draining CSF and immune cells drain through the meningeal lymphatic system into peripheral deep cervical lymph nodes to activate and prime T cells [5, 33, 48].

$\mathrm{T}$ cells develop in the thymus through the expression of $\mathrm{T}$ cell receptors and glycoproteins. CD8 and CD4 glycoprotein expressing cells are naïve CD8+ and CD4+ T cells. Upon activation, the latter, CD4+ T cells, differentiate into effector subsets exerting diverse immune responses. These subsets include T helper 1 (Th1), Th2, Th9, Th17, Th22, follicular helper T cells (Tfh), and Tregs. Each CD4+ subset secretes cytokines with either pro- or anti-inflammatory functions. Th1 cells secrete IL-2, interferon gamma (IFN- $\gamma$ ), and tumor necrosis factor (TNF); Th2 cells secrete IL-4, IL-5, IL-10 and IL-13; Th9 cells secrete IL-9; Th17 cells secrete IL-17, and Tregs secrete IL-10 and transforming growth factor beta (TGF- $\beta$ ). Different cytokines secreted from CD4+ subsets drive effector or regulatory immune responses. Among different CD4+ effector subsets, Th1 and Th17 cells drive proinflammatory responses while Tregs exert anti-inflammatory and immunosuppressive activities. A balance between both pro- and anti-inflammatory immune responses is essential to maintain generalized homeostasis and especially within the CNS where an imbalance can lead to disease $[2,49]$. Except Tregs, although all the CD4+ T cells are considered effector subtypes, herein, pro-inflammatory and neurodestructive functions are included in groups of Th1 and Th17 cells defined as Teffs, whereas Treg functions are described as antiinflammatory, immunosuppressive and neuroprotective (Fig. 1).

\section{Microglia}

Microglia are CNS innate immune cells which play indispensable roles in affecting neuronal homeostasis and in promoting $\mathrm{T}$ cells responses in the brain. Macrophages, the prototype peripheral innate immune cell adopt M1 (classically pro-inflammatory activated) and M2 (alternatively anti-inflammatory activated) phenotypes [50]. Similarly, microglia also exhibit functional plasticity that leads to their altered cell number, morphology, surface receptor expression, and growth factor and cytokine secretion [51]. Microglia shift into an M1 or an M2 phenotype depending on the surrounding immune environment [52]. Pro-inflammatory microglia secrete increased TNF- $\alpha$, IL-6, IL-1 $\beta$, neurotoxic reactive oxygen species (ROS), nitric oxide, and reduced neurotrophic factors that additively injure neuronal cells [53, 54] (Fig. 2). Whereas, anti-inflammatory microglia secrete IL-4, IL-13, TGF- $\beta$, and neurotrophic factors, like insulin-like growth factor 1 (IGF-1) that induce phagocytosis of protein aggregates collectively attributing to neuroprotection [53, 54]. Astrocytes, another abundant innate immune cell, also play diverse anatomical and functional roles inside the CNS [55]. Like microglia, astrocytes in neuroinflammatory and ischemic conditions acquire A1 and A2 phenotypes that secret neurotoxic pro-inflammatory mediators and neurotrophic factors, respectively. However, these secreted molecules are not well-identified [56-58].

Microglia phenotypes are not absolute and the cell's morphology and functional changes that occur during physiological and diverse pathological conditions determine outcomes. Studies of human postmortem microglia revealed that due to the brain's microenvironment, they acquire multiple phenotypic signatures affected by location [59]. Markers for microglial proliferation and activation, for example, are seen readily in the subventricular zone and thalamus. These reflect regional heterogeneity. Immune profiling of postmortem human microglia are generally comparable to cells freshly isolated and from other species [60]. However, during disease, such as experimental allergic encephalomyelitis (EAE), microglial subsets are linked to brain function and disease. Two subsets are critical for brain homeostasis while four others are disease associated. All microglial subsets share the P2RY12 ${ }^{\text {lo }}$ TMEM $119^{\text {lo }} \mathrm{MD}-1^{\text {hi }}$ profile and express specific chemokine, cytokine and cysteine receptors and proteases that suggest broad cellular dynamics [61]. Heterogeneous microglia are seen in Huntington's disease, EAE and ALS demonstrating unique molecular signaling and cytokine signatures [62]. Although the advanced high throughput single-cell RNAseq and mass cytometry have uncovered microglial heterogeneity in the setting of disease and homeostatic function, whether it is sufficient to define different subtypes is unknown. The identification of unique microglial function associated with each subset at disease may define the role microglia play in health and disease $[63,64]$. Likewise, 


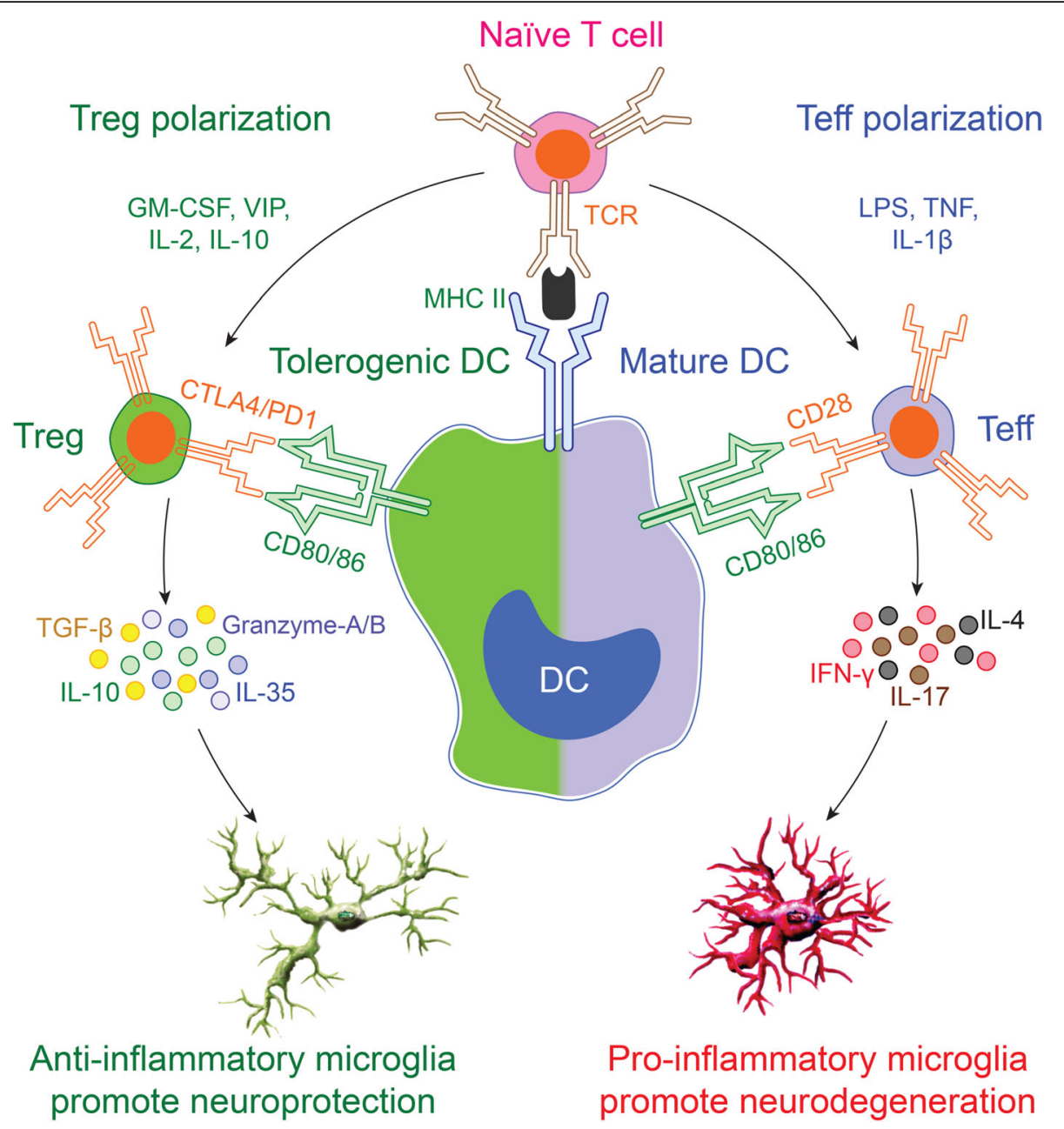

Fig. 1 DCs and T cell polarization. Immature DCs take up antigen, process and present it to immunocytes. Antigen uptake induces maturation signals in DCs in cooperation with the upregulation of co-stimulatory molecules. Mature DCs encounter naiive T cells through MHCII-T cell receptor (TCR) interactions, leading to T cell activation, Teff differentiation, and secretion of pro-inflammatory molecules (IL-10, L-35, TGF- $\beta$, granzymes, etc.). In contrast, some DCs can maintain central and peripheral immune tolerance called tolerogenic DCs. The tolerogenic DCs exhibit low levels of costimulatory molecules and as such, provide insufficient stimulatory signals to naïv T cells to induce Treg and anti-inflammatory cytokines (IL-4, LL17, IFN- $\gamma$, etc.). Tregs suppress Teff function and proliferation to maintain immune tolerance. Teffs secreted molecules govern pro-inflammatory microglia polarization. In contrast, Tregs favor anti-inflammatory microglia polarization, supporting neuroprotection. Balance between Teffs and Tregs is essential to maintain homeostasis while their imbalance leads to neurodegeneration through microglia responses

astrocyte phenotypes are not absolute; and it is still unclear what possible signaling pathways are involved [56, 57]. Both, microglia and astrocytes under normal circumstances recognize pathogenic signals and respond through different cytokine and chemokine milieu that ultimately determines immune responses [65].

\section{Gut microbiota and neuroimmunity}

The dynamic population of microorganisms, including bacteria, viruses, fungi, and archaea, that reside inside the gastrointestinal tract play an indispensable role in homeostasis. Alterations in the composition of the gut microbiota called dysbiosis, lead to the development of metabolic, autoimmune, and neurodegenerative diseases
[66, 67]. Recent studies established the link between gut dysbiosis and inflammatory changes of different organs including the brain $[66,68]$.

Human and animal model studies have shown that increased frequency of pathological bacteria or absence of useful bacterial components in the gut associated with neurodegenerative diseases including MS, AD, PD and ALS. A study with 34 pairs of discordant MS twins found differences in the gut microbiota composition compared to healthy counterparts. Furthermore, MS twin-derived microbiota increased disease severity in animal models that develop spontaneous brain autoimmunity, compared to the healthy twin-derived microbiota [69]. 


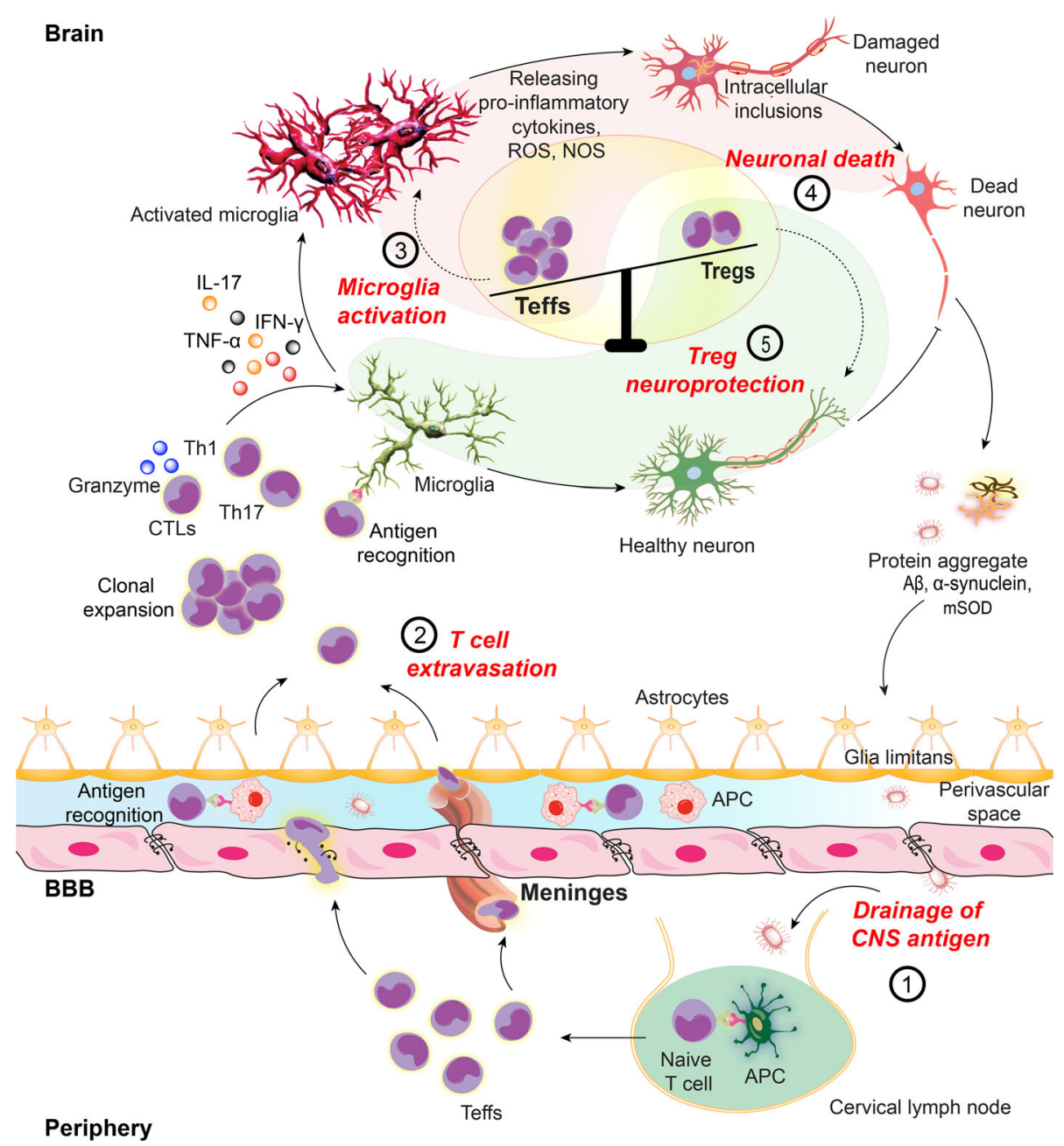

Fig. 2 Teff activities promote neuroinflammation. In neurodegenerative disorders, CNS antigens including A 3 , a-syn, mSOD and MBP provoke microglia immune responses leading to neuroinflammatory cascade in affected brain regions. (1) Self-antigen or misfolded proteins are generated from damaged neuronal cells. The neural antigens drain to the peripheral lymphoid nodes by meningeal lymphatic vessels where they are taken up by local APCs including macrophages and DCs. Natural self-antigens are presented to peripheral T cells in MHCIl dependent manner. (2) Naïve T cells, upon recognition of cognate antigen, differentiate into antigen-specific Teffs. Reactive microglia secrete cytokine-chemokine milieu to upregulate cell adhesion molecules (CAM) by blood-brain barrier (BBB) endothelial cells, opening the gate for peripheral primed T cells. Teffs (Th1 and Th17) with upregulated integrins and CAM ligands readily cross the BBB. Teffs also cross the blood-CSF barrier through choroid plexus meninges. After extravasation into the brain, Teffs are reactivated upon recognition of cognate antigen on common CNS APCs. These include perivascular macrophages (PVMs), choroid plexus and meningeal macrophages and DCs and parenchymal microglia. $(3,4)$ Activated Teffs secrete pro-inflammatory and neurotoxic mediators to polarize microglia to a higher activation state, producing pro-inflammatory cytokines and reactive oxygen and nitrogen species which further perpetuate the inflammatory cascade to induce neurotoxicity. (5) Tregs maintain immune tolerance by suppressing effector immune responses. Naïve T cells can also differentiate into Tregs upon recognition of cognate antigen on peripheral APCs in secondary lymphoid tissues. Differentiated Tregs exert neuroprotective responses through multiple mechanisms. The inflammatory immune responses observed in neurodegenerative disorders are the outcome of Teff-Treg imbalance with upregulated Teff responses

Gut dysbiosis is also implicated in AD pathogenesis. Recently, fecal microbiota compositions of AD patients and age- and sex-matched normal controls were found significantly different. Several bacterial taxa including Bacteroides, Actinobacteria, Ruminococcus, Lachnospiraceae, and Selenomonadales were different in AD patients from controls [70]. In AD animal studies, intestinal dysbiosis speeds cognitive decline and neurodegeneration [71, 72]. In PD patients, gut dysbiosis with elevated harmful microbial taxa including Proteus mirabilis promoted dopaminergic neuronal death and motor impairment [73]. PD patients derived microbiota enhanced severity of motor symptoms in $\alpha$-synucleinoverexpressing mice compared to healthy donor microbiota. The short-chain fatty acids (SCFA) produced from gut microbiota may activate certain immune cells that promote $\alpha$-synuclein aggregation and microgliosis to impair motor symptoms [68]. On the other hand, butyrate 
producing bacteria, Butyrivibrio fibrisolvens were found selectively reduced in the gut microbiota of mice genetically susceptible to ALS. Here butyrate treatment significantly attenuated disease severity [74]. Neuroprotective effects of butyrate were also reported in the 1-methyl-4phenyl-1,2,3,6-tetrahydropyridine (MPTP) model of PD $[75,76]$.

CD4+ $\mathrm{T}$ cells mediate crosstalk between gut microbiota and the CNS. Microbiota and their secreted molecules including SCFA, neurotransmitters, and other metabolites affect differentiation and expansion of proand anti-inflammatory CD4+ T cells. Commensal microbes, such as segmented filamentous bacterium, induce pro-inflammatory Th17 cells [77] while Bacteroides fragilis directs the development of immunosuppressive Tregs [78]. In addition, SCFA, butyrate and propionate favor the expansion and immunosuppressive activity of Tregs [79]. Amongst microbiota secreted neurotransmitters, glutamate favors Th1-mediated immune responses while $\gamma$-aminobutyric acid attenuates Th1 responses and favors Treg activity [80]. It is likely that autoreactive CD4+ T cells, activated after encountering cognate antigens in the gut-associated lymphoid tissues and leading to dysbiosis, promote the acquisition of Teffs, such as Th1 and Th17 [66, 81].

Considerable evidence supports the role of gut microbiota on microglial function and phenotype [67, 82]. Germ-free mice displayed global microglial defects with abundant immature phenotypes [83]. Similarly, native microbiota elimination using antibiotic treatment disrupted microglial maturation evidenced by defective inflammatory gene profiles [84]. Mice exhibiting innate immune cells lacking the free fatty acid receptor 2 (FFAR2) for microbiota's SCFA also displayed microglial defects. However, recolonization of complex microbiota partially restored microglial defects in germ-free mice [83]. Overall, gut microbiota serves as a clinically feasible target to restore altered innate and adaptive immune responses in different neurodegenerative conditions.

\section{Dendritic cell role in $\mathrm{T}$ cell maturation}

The orchestrator of adaptive immune responses is the DC that serves as the body's key APC participating in immune surveillance and $\mathrm{T}$ cell differentiation. Immature DCs encounter antigen through innate pattern recognition receptors (PRRs) such as membrane bound toll-like receptors (TLRs) or cytosolic nucleotide-binding oligomerization domain-like receptors (NLR) and take up antigen by micropinocytosis and phagocytosis. DCs process antigen by proteolytic (endolysosomal and proteosomal) machinery and degrade it into small peptide fragments that bind to major histocompatibility complex (MHC) molecules on the DC surface. The MHC-peptide complexes then present to immunocytes for antigenic- specific stimulations [85, 86]. Although monocytemacrophages and B cells can also present antigen in a MHC-dependent manner, DCs are unique with the ability to activate naïve $\mathrm{T}$ cells and induce antigen-specific immunity [85, 87]. Antigen uptake produces a maturation signal by DCs resulting in upregulation of costimulatory molecules like CD40, CD80, and CD86 and secretion of pro-inflammatory signal 3-type cytokines that include IL-6, IL-12, IL- $1 \beta$, and TNF- $\alpha / \beta$ [88]. To encounter naïve $\mathrm{T}$ cells in the secondary lymphoid organs, DCs upregulate expression of $\mathrm{C}-\mathrm{C}$ and $\mathrm{C}-\mathrm{X}$ chemokine receptors on their surface that facilitate their secondary lymph node migration [89]. T cell-DC activation involves a three-signal process. First, recognition of cognate antigen on DCs' MHC by the TCR. Second, engagement of the CD28 $\mathrm{T}$ cell co-receptor with co-stimulatory molecules CD80/86 on DCs. Third, interaction of DC-produced cytokines with their receptors on immunocytes [90]. Upon activation and antigen recognition, naïve $\mathrm{T}$ cells differentiate into Teffs facilitating pro-inflammatory immune responses $[88,91]$.

DCs also maintain central and peripheral immune tolerance. This is attributed to DCs Treg polarizing capability. DCs, termed tolerogenic DCs, can phagocytize self-antigen from apoptotic cells to silence auto-reactive $\mathrm{T}$ cells [86]. Tolerogenic DCs display immature or semimature phenotypes characterized by low expression of MHC and co-stimulatory molecules and secretion of abundant anti-inflammatory cytokines like IL-10, IL-13, and TGF- $\beta$ and abrogated pro-inflammatory cytokines. Due to low expression of co-stimulatory molecules, tolerogenic DCs evoke insufficient stimulation signals and therefore differentiate naïve $T$ cells into Tregs instead of Teffs $[86,92]$. Both Tregs and Teffs have differential effects on microglia to induce either neuroprotection or neurodegeneration [2, 3] (Fig. 1). The least immune tolerogenic DCs can be induced by immunosuppressive agents and cytokines. IL-10 and TGF- $\beta$ downregulate MHC and co-stimulatory molecules on DCs, altering their antigen-presentation capabilities and inducing PDL-1 expression and T cell anergy [93]. DCs can also suppress Teff proliferation by immunosuppressive mechanisms shared with Tregs [94]. The immunomodulatory, VIP, attenuates complete maturation of DCs and induces IL-10 secretion [95]. GM-CSF alters expression of costimulatory molecules, pro-inflammatory cytokines, and chemokines on DCs that orchestrate immune transformation from Teff into Tregs [96]. Vitamin D3, hepatocyte growth factor, and complement factor $\mathrm{H}$ can also induce tolerogenic DCs, which favor Treg polarization [97-99]. Depending upon the state of activation and surrounding microenvironment, DCs favor either Teffs or Tregs to induce antigen-specific immune responses. Thus, DCs 
mount timed-relevant immune responses by bridging innate and adaptive immune systems [87, 94].

\section{Effector and regulatory $\mathrm{T}$ cells in neurodegenerative disorders}

Breaking immunological tolerance through modified or misfolded self-proteins has re-defined the role of autoimmunity in neurodegenerative disorders $[3,100]$. CNS draining self-antigens prime peripheral $\mathrm{T}$ cells to extravasate inside the brain where $\mathrm{T}$ cells are reactivated through cognate antigen recognition and release specific cytokines and chemokines to facilitate extensive local inflammatory reactions. Compromised BBB integrity allows further infiltration of peripheral effector leukocytes [5, 34]. Cytotoxic T lymphocytes (CTLs), T-bet expressing Th1, and ROR $\gamma$ expressing Th17 cells, all Teffs driven neuroinflammatory responses are well-established in various neurodegenerative conditions [1-3]. Several studies have described effects of infiltrating $\mathrm{T}$ lymphocytes on microglia and neuronal cells. Teffs (Th1 and Th17) influence and maintain microglia proinflammatory phenotypes via secretion of IFN- $\gamma$ and IL17 or release of granzyme B [101, 102]. Myelin-specific $\mathrm{T}$ cells were observed in direct contact with reactive IL$1 \beta+$ microglia in the EAE model of MS [103]. Similarly, infiltrating $\mathrm{T}$ lymphocytes are found in close proximity of activated microglia with direct neuronal interaction in the substantia nigra (SN) in the MPTP model of PD [1, 13, 29]. In a similar model, overexpression of MHCII on microglia was found after phagocytosis of neuronal tracers to directly interact with infiltrated $\mathrm{T}$ lymphocytes [104]. Infiltrated T lymphocytes were observed closely aligned with microglia cells in AD brains [105] where microglial MHCII upregulation corelated with disease progression [106]. The MHCII+ microglia process and present self-antigens to reactivate $\mathrm{T}$ lymphocytes that underscore Teff responses on neurodegenerative processes through innate immunity [2]. Like microglia, astrocytes can also interact with $\mathrm{T}$ lymphocytes by upregulating $\mathrm{MHC}$ and co-stimulatory molecules [107, 108]. Although compared to professional APCs, T cell priming capabilities of astrocytes are relatively weak; hence, direct interaction between astrocytes and reactive $\mathrm{T}$ lymphocytes has yet to be confirmed in most neurodegenerative conditions. Studies revealed that IFN- $\gamma$ stimulated astrocytes cultured from EAE mice upregulated processing and presentation of myelin epitopes to induce Th1 cell differentiation from myelin-specific naïve $\mathrm{T}$ cells $[109,110]$. Bechmann et al. showed co-localization of astrocytes with $\mathrm{T}$ cells in vivo and the ability of astrocytes to induce apoptosis of transformed $\mathrm{T}$ cells through the CD95/CD95L pathway [111]. In addition to direct priming $\mathrm{T}$ cells, astrocytes may also govern $\mathrm{T}$ cell activation and differentiation through instructive cytokines or unidentified molecules including IL-1, IL-6, TNF- $\alpha$, IL10 , and TGF- $\beta$ responsible for Teff and Treg differentiation $[107,108]$. $T$ cells can also affect astrocyte phenotypes. Th1 secreted IFN- $\gamma$ has been established as potent stimuli for astrocytes [112]. T cell-derived IL-9 interaction with IL-9R complex on astrocytes was reported to upregulate surface chemokine CCL20 on astrocytes that facilitate Th17 cell transmigration across the BBB [113]. Additionally, direct neurotoxic effects of Teffs have been reported through cell-contact dependent mechanisms and signaling through FasL, LFA-1, and CD40 [114]. Neurotoxicity of Th17 Teffs are well established in MPTP mice $[1,115]$. Th17 cells infiltrate into the SN and exacerbate dopaminergic neuronal death through direct contact of leukocyte function-associated antigen (LFA)-1 on Th17 cells with intercellular adhesion molecule-1 (ICAM-1) on neuronal cells. Blocking of either LFA-1 or ICAM-1 using a neutralizing antibody abolished Th17-mediated neurotoxicity, verifying the mechanism of action [115].

In opposite to Teffs, Tregs offer neuroprotective responses. Tregs are a naturally occurring $\mathrm{T}$ lymphocyte subpopulation identified by the expression of cell surface markers CD4 and CD25 (IL-2R $\alpha$ ) and the transcription factor forkhead box protein P3 (FOXP3). Tregs, derived thymically or generated peripherally from the naïve $\mathrm{T}$ cells upon antigenic stimulation, play an important role in immune homeostasis and antigen-specific immune tolerance by suppressing effector immunity against a divert range of antigens, including those derived from self, commnensal bacteria, and the environment $[100,116]$. Tregs downregulate the activities of different immune cells including Teff function and proliferation through several mechanisms. To suppress Teff functions, Tregs release immunosuppressive cytokines including TGF- $\beta$, IL-10, and IL-35 or induce direct cytotoxicity and apoptosis by releasing granzyme $\mathrm{B}$ and perforin 1 . Tregs can also suppress Teff function indirectly through immunoregulatory molecules like cytotoxic $\mathrm{T}$ lymphocyte antigen 4 (CTLA4), CD39, and CD73 creating metabolic disruption or by abrogating maturation or antigenpresenting capabilities of APCs. Additionally, as relatively anergic cells, CD25+ (IL-2R) Tregs can adsorb IL2 from the surrounding environment, concomitantly precluding IL-2 for growth necessitated by CD25+ Th1 and CD8+ Teffs $[12,100,116]$.

Emerging evidence suggests alterations in the peripheral adaptive immune system and inflammatory markers in diverse immunological diseases mainly characterized by increased Teff and reduced Treg frequencies or function $[5,9]$. However, studies over the past decade warrant that such immune alterations are not limited to the periphery, but also extend to the CNS playing a detrimental role in the development of neurodegenerative 
disorders [2, 3]. Although Tregs have been characterized in the periphery, recent advancements have enabled study of this tiny population inside the brain as well [33, 48]. Tregs exhibiting an activated memory phenotype have been identified in the brain. This phenotype helps Tregs to suppress local effector immune responses and ameliorate neuroinflammation [116, 117]. During the initial disease stage, the compromised BBB further allows the entry of $\mathrm{T}$ lymphocytes, including Tregs, that contribute to CNS immunity [116]. However, over disease progression, the frequency and immunosuppressive properties of Tregs are diminished, shifting balance between Tregs and Teffs, specifically towards IFN- $\gamma$ producing Th1 and IL-17 producing Th17 cells, leading to a breakdown of immune tolerance $[3,118]$. In addition to suppressing the function and proliferation of Teffs, Tregs maintain anti-inflammatory microglial and astrocyte phenotypes through the release of IL-4, IL-10, and TGF- $\beta[12,54,119]$. Tregs suppress microglial synthesis and release of ROS, and facilitate astrocyte glial cellderived neurotrophic factor (GDNF) and brain-derived neurotrophic factor (BDNF) secretion [22, 29]. Tregs also protect neurons directly using cell-contact dependent mechanisms via CD47 and signal regulatory protein- $\alpha$ (SIRPA) [120] or by releasing neurotrophic factors such as BDNF [12, 52]. Neuronal cells can also interact directly with microglia via the CD200-CD200R mechanism [54, 121]. Neuronal ligand CD200 interact with microglia receptor CD200R to induce an antiinflammatory microglial phenotype that attracts Tregs by release of chemokines, possibly $\mathrm{C}-\mathrm{C}$ chemokine ligand 2 (CCL2) and CCL5 [54, 122].

Tregs also have regenerative activities in tissues that include the retina [123], kidney [124], and skin [125]. This is seen through the control of tissue-specific inflammatory responses as well as through direct regenerative responses. Indeed, depletion of Tregs has been shown to augment tissue damage and mortality and affect vascular repair in these tissues. Although reparative functions of Tregs are not fully characterized in the brain due to their lower frequency, recent advancements have established functional role of Tregs in brain repair. The regenerative potential of Tregs was found through direct differentiation of oligodendrocyte progenitor cells that promote remyelination in the absence and presence of overt inflammation. Treg-derived cellular communication network factor 3 (CCN3), a growth regulatory protein, was identified as a key driver of oligoprogenitor cell differentiation and CNS remyelination [18]. Recently, brain reparative potential of peripheral Tregs was seen in ischemic stroke. In chronic disease phase, infiltration of peripheral Tregs increased in the ischemic mouse brain that efficiently suppressed neurotoxic astrogliosis by producing amphiregulin, a low-affinity epidermal growth factor receptor ligand that induced neuronal recovery from ischemic inflammatory responses [119]. However, these findings do not rule out additional indirect mechanisms of Treg neuroprotection and repair.

Both Tregs and Teffs are crucial in maintaining systemic as well as central immune homeostasis; therefore, preservation of these immune cell frequency and function can control neurological diseases [2, 3] (Fig. 2). Several studies have shown the peripheral emergence of Teffs followed by their infiltration into the CNS with concurrent downregulation of Treg function and frequency in different neurodegenerative disorders $[1,126]$. Here, we have summarized the effects of Treg-Teff imbalance in several diseases and how restoring its balance can improve conditions.

\section{Multiple sclerosis (MS)}

CNS-antigen specific immune responses were first identified in MS patients and in EAE animals. The prime etiology of this autoimmune disease is loss of self-tolerance that allows development of functional autoreactive lymphocytes against their cognate antigen [2,3]. In attempt to decrease autoreactive cells, MS patients were injected with modified self-peptide. Surprisingly, treatment enhanced autoreactive Th1 responses and triggered development of newer inflammatory lesions. This clinical trial outcome provided evidence of $\mathrm{T}$ cell epitope spreading and their direct role in CNS defects in MS [127]. In MS, disease specific Teff frequency increases in the periphery that subsequently infiltrate into the CNS. MS patients showed increased peripheral Th1 and Th17 cells along with their associated cytokines including IL$1 \beta$, IL-6, IL-17, TNF- $\alpha$ and IFN- $\gamma[34,128]$. Increased frequencies of myelin basic protein (MBP)- and myelin proteolipid protein (PLP)-reactive CD4+ and $\mathrm{CD} 8+\mathrm{T}$ lymphocytes were observed in the peripheral blood and CSF of MS patients. IL-2 stimulation further increased autoreactive $\mathrm{CD} 4+\mathrm{T}$ cell frequency in MS patients [129].

Additionally, autoreactive CD4+ and CD8+ T cells were found in post-mortem diseased brains but not in healthy controls [130]. In the CSF and brain parenchyma of MS patients, IFN- $\gamma$, IL-17 and IL-22 were elevated compared to controls. Activated CD4+ T cells simultaneously expressing IFN- $\gamma$ and IL-17 were predominantly expanded in MS patients' blood during relapse phase. This study demonstrated a greater capacity of these cells to invade the $\mathrm{BBB}$ as evidenced by histopathological examination of post-mortem MS brain tissues [131]. In EAE models of human disease, adaptive immune responses can be induced either by subcutaneous immunization with myelin antigens or by adoptive transfer of in vitro myelin-activated CD4+ $\mathrm{T}$ cell subsets, 
mainly consisting of IFN- $\gamma$-producing Th1 cells and IL17-producing Th17 cells [132, 133]. In rodents, immunization with MBP peptides activated myelinspecific $\mathrm{T}$ cells in the periphery with concomitant infiltration of $\mathrm{T}$ lymphocytes into the brain. Infiltrated Teffs, specifically Th1 and Th17, accumulated in the brain parenchyma and initiated demyelination. Likewise, the adoptive transfer of induced Teffs progressed disease in the naïve recipient [134]. Adoptive transfer of encephalitogenic Th1 and Th17 cells induced CNS lesions with distinct patterns $[135,136]$. The predominance of Th1 or Th17 responses in MS patients has been implicated in disease heterogeneity with variation in clinical scores, responses to immune therapies, and localization of CNS lesions $[137,138]$. Thus, studies demonstrated extravasation of peripheral Teffs into the CNS that orchestrate autoimmune neuroinflammatory responses in EAE and MS. Although the key role of Th1 and Th17 Teffs in the progress of MS and EAE are well established, the mechanisms whereby these cells contribute to the pathogenesis are not completely understood. The possible mechanism of breakdown of self-tolerance might be attributed to Teff induced altered Treg frequencies and function $[2,3]$.

Contrary to increased Teff frequency, the number, function, and migratory capabilities of Treg are compromised in the MS patients. Although significant differences in the number of circulating Tregs between MS patients and healthy controls are not always observed, isolated Tregs have lower suppressive activity as frequently reported, suggesting a functional Treg deficit contributes to a breakdown of immune tolerance in MS $[139,140]$. A recent meta-analysis study demonstrated that the frequency of peripheral Treg defined as CD4+CD25+FOXP3+ significantly decreased in MS patients compared to control subjects [141]. No differences were observed when Tregs, defined by only $\mathrm{CD} 4+\mathrm{CD} 25+$, suggesting the importance of FOXP3 as a vital Treg marker that plays a key role in maintaining immunosuppressive functions. Restoring Treg frequency and function has shown promising results in disease outcomes. IL-10 gene therapy in EAE significantly increased Treg frequency by modulating DCs. This resulted in improved clinical symptoms and attenuated gliosis in the brain [142] possibly through IL-10 induced DC tolerance that has the ability to increase Treg frequency and function. Treg depletion attenuated the protective effects offered by intravenous immunoglobulin (IVIg) in EAE [143]. Furthermore, VIP administration expanded Tregs in the periphery and the CNS and simultaneously inhibited encephalitogenic $\mathrm{T}$ cell activation and abrogated disease progression [144]. Of note, VIP is a potent inducer of tolerogenic DCs which can increase Treg frequency and function in a cytokine-dependent manner
[95]. Fingolimod, an immunomodulator that inhibits CNS ingress of lymphocytes from lymph nodes and their recirculation and is approved for the treatment of MS, has also been reported to reduce circulating IFN- $\gamma$ and IL-17 secreting Teffs and increase the number of circulating Tregs in MS patients [145, 146].

Over the past decades, our understanding of neuroinflammation has increased beyond its role in classical autoimmune diseases like MS. Research efforts have now established the role of adaptive immune alterations (Tregs and Teffs) in the pathogenesis of classical neurodegenerative disorders including $\mathrm{AD}, \mathrm{PD}$ and ALS, and related vascular and viral-based neuronal injuries, stroke and HIV-1 associated neurocognitive disorders (HAND) respectively.

\section{Alzheimer's disease (AD)}

$\mathrm{AD}$ is the most common cause of dementia in the elderly. AD affects an estimated 40 million people worldwide, and this is expected to double every 20 years until at least 2050 [147]. The disease is mainly characterized by the extracellular deposits of $A \beta$ plaque and intraneuronal neurofibrillary tangles (NFTs) of tau triggering degeneration of cholinergic neurons in the brain (Fig. 3) $[17,148]$. Although most $\mathrm{AD}$ research is progressing around the amyloid hypothesis, recent findings have argued the role of sustained inflammation secondary to misfolded protein accumulation that affect microglia and neuronal cell functions. Innate and adaptive immune alterations play a key role in driving such neuroinflammatory responses [2, 3, 17]. Active $A \beta$ immunization showed promising results in preclinical testing that abrogated amyloid deposits and improved cognitive functions [149]. However, a phase 2a clinical trial (NCT00021723) testing immunization with full length $\mathrm{A} \beta$ and QS21 adjuvant (AN1792) was paused after the observation of meningoencephalitis in $6 \%$ of patients. Later, the adverse effects were found to be attributed to the proinflammatory $\mathrm{T}$ lymphocyte infiltration into the brain parenchyma [150]. In contrast, A $\beta$-specific CD4+ T cells have shown to promote $A \beta$ clearance and reverse cognitive decline in AD mouse models [151, 152]. Therefore, $\mathrm{CD} 4+\mathrm{T}$ cells can be detrimental or protective depending upon their effector or regulatory phenotype.

Increased frequency of circulating Teffs and their subsequent transmigration into the brain parenchyma has been observed in AD patients and murine models [105, 126]. During AD progression, brain amyloidosis alters the expression of vascular adhesion molecules that enhance the transmigration of peripheral immune cells into the brain [153]. Increased numbers of infiltrating $\mathrm{T}$ cells were observed in amyloid-burdened brain regions of $\mathrm{AD}$ transgenic mice with concomitant up-regulation of endothelial adhesion molecules ICAM-1 and vascular 


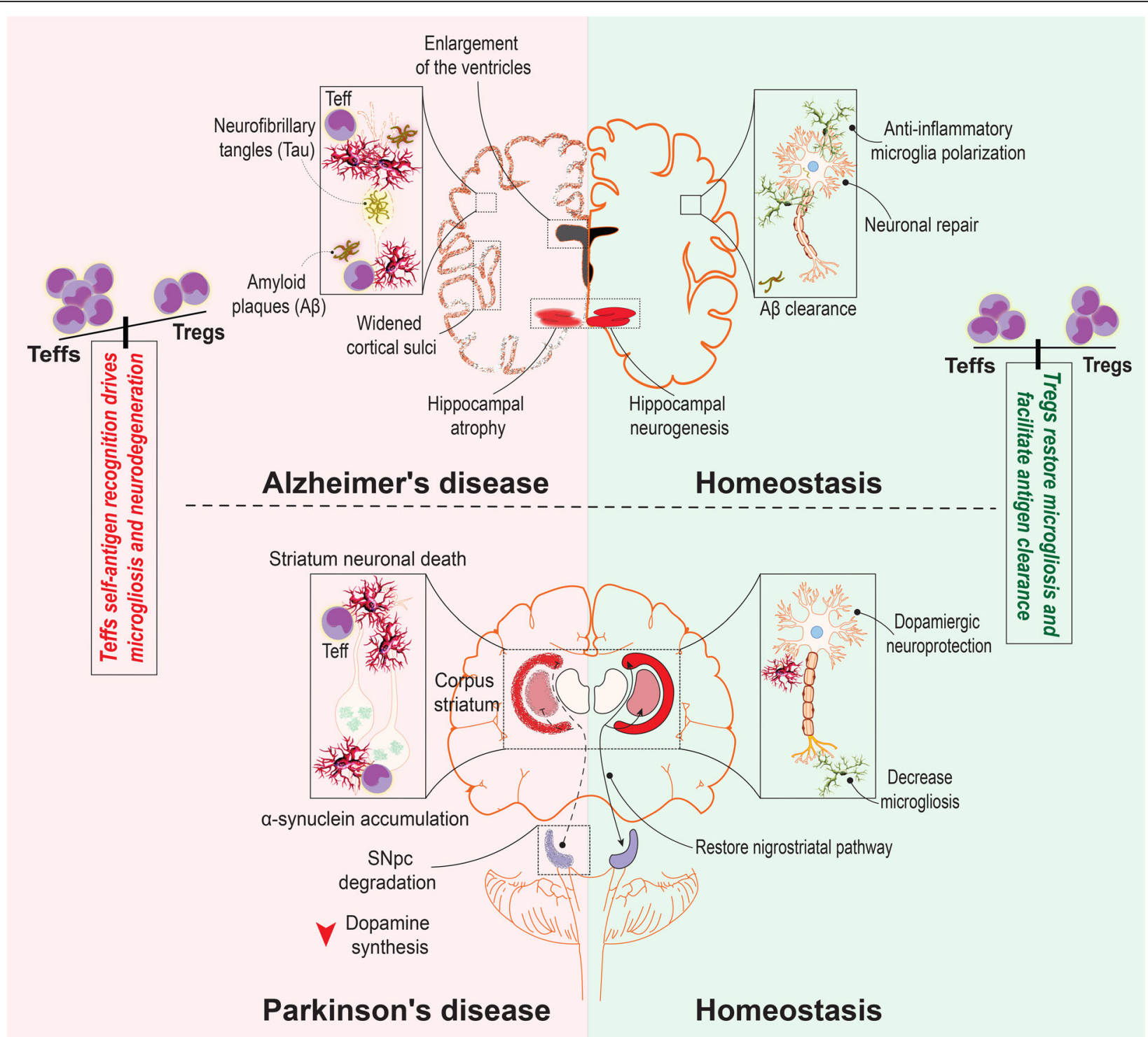

Fig. 3 Teff and Treg immunity in AD and PD. Pathogenic changes observed in AD brain include accumulation of intraneuronal neurofibrillary tangles (NFTs) of Tau protein and extracellular amyloid beta (Aß) plaques. The accumulated peptides facilitate neuroinflammatory Teff entry into the brain where they affect resident microglia cells to induce local inflammatory responses. In PD, a-synuclein accumulation promotes immunoreactive Teff entry into the brain to activate microglia, compromising nigrostriatal axis between the substantia nigra pars compacta (SNpc) and striatum that execute motor commands. Immunoregulatory Tregs can restore homeostatic balance in the brain through clearance of neuroimmunogens, microglial polarization and restoration of normal neural functions

cell adhesion molecule-1 (VCAM-1) compared to nontransgenic littermates. Infiltrated $\mathrm{T}$ cells do not proliferate locally nor release less IFN- $\gamma$, but interfere with local antigen presentation and $\mathrm{T}$ cell activation, suggesting their inability to contribute protective immunity in the amyloidogenic brain [154].

It was also shown that Bordetella pertussis respiratory infection amplified migration of IFN- $\gamma$ - and IL-17producing $\mathrm{T}$ cells and NK T cells in the brain of older human amyloid precursor protein (APP) and presenilin 1 (PS1) double transgenic (APP/PS1) mice. Later, this process was confirmed to be age-dependent and, showed significantly higher numbers of Th1 and Th17 cells in older APP/PS1 mice with parallel gliosis [155]. Common infectious pathogens that include cytomegalovirus, herpes simplex virus type 1, Borrelia burgdorferi, Chlamydophila pneumoniae and Helicobacter pylori were found associated with elevated systemic inflammation and amyloid burden in AD patients [156, 157]. Chronic infection with these agents also developed cerebrovascular disorders [158] that subsequently promoted AD pathology [159] in patients. Thus, chronic infection and 
persistent peripheral inflammation may be associated with increased $\mathrm{T}$ lymphocyte migration into the brain that lead to autoimmune neurodegeneration.

Brown et al. observed significant infiltration of IFN- $\gamma$ and IL-17-secreting $\mathrm{T}$ lymphocytes in APP/PS1 mice brain. Additionally, adoptive transfer of $A \beta$-specific Th1 cells, but not Th2 and Th17 cells, increased microglia activation and amyloid deposition that led to early cognitive impairment in mice [160] suggesting a key role of antigen-specific Teff responses in propagating an inflammatory cascade to further disease pathology. Interestingly, both IFN- $\gamma$-secreting $\mathrm{CD} 4+$ as well as CD8+ T lymphocytes were detected in the CNS following adoptive transfer of $A \beta$-Th1 cells reflecting a key role of both $\mathrm{T}$ cell subsets in AD progression. Recently CD4+ and CD8+ lymphocytes were found patrolling the CSF in AD patients with clonal expansion of CD8+ Teffs $[161,162]$. Extravasation of CD4+ and CD8+ Teffs was observed in the brains of postmortem AD patients compared to controls who died of non-neurological diseases [105, 126, $161,163]$. Overall, a clear association of adaptive immunity in the neuropathogenesis of AD was demonstrated.

Apart from CNS, peripheral immune alterations are likely candidates for early biomarker studies in different neurodegenerative diseases including AD. Peripheral blood analysis of $\mathrm{AD}$ patients showed elevated frequencies of CD4+ and CD8+ T lymphocytes [161, 162]. Saresella et al. first observed elevated levels of ROR $\gamma+$ Th17 cells in AD patients' blood compared to those with mild cognitive impairments (MCI) and age-matched controls. However, Th1-associated transcription factor T-bet and cytokines were unchanged. Despite increased effector memory and terminally differentiated lymphocytes in both disease patients (AD and MCI), authors selectively identified peripheral Th17 cell activation as an important immunological marker to differentiate $\mathrm{AD}$ and MCI patients [164]. Later Agnes et al. showed increased proportion of Th17 cells and their direct involvement in the systemic inflammatory functions in AD patients [165] further supporting Th17 Teffs as a potential biomarker. Peripheral blood IL-17, a key Th17 cell cytokine, can weaken tight junctions of the BBB and facilitate peripheral leukocytes extravasation into the brain inducing pro-inflammatory cytokines TNF- $\alpha$, IL- $1 \beta$, and IL- 6 in $\mathrm{AD}[166,167]$. In line with previous reports, Oberstein et al. recently suggested an early role of peripheral Teffs in disease progression. Authors observed increased circulating Th17 cells in early stage AD patients exhibiting MCI that correlated to amyloidopathy [168]. Another study also revealed direct $A \beta$ effects on Th17 cells cytokine expression [169]. Intrahippocampal $A \beta_{1-42}$ injection in rats disrupted $\mathrm{BBB}$ integrity that allowed peripheral ROR $\gamma+$ Th17 cell infiltration at the injection site as evidenced by elevated IL-17 and IL-22 expression in the hippocampus. These cytokine levels were also elevated in CSF and serum. Additionally, infiltrated Th17 cells induced direct neurotoxicity via the Fas-FasL apoptotic pathway. With elevated circulating CD4+ Teff frequency, downregulated Treg frequency was also reported [170].

The idea of counteracting effector immune responses using Tregs is still controversial in $\mathrm{AD}$ pathogenesis. Naturally occurring Tregs were reported to interfere with ability of retinal ganglion cells to counterattack aggregated $A \beta$ toxicity and depletion of Tregs helped revitalize retinal neuronal tissue [171]. Increased Treg frequency and their suppressive function in aging $A D$ patients were also reported [172]. Treg immunosuppression impaired phagocytic capabilities of brain resident innate immune cells and affected amyloid plaque clearance in an AD mouse model [173]. Despite these facts, most evidences support the protective effects of Tregs in AD. Recently, Ciccocioppo et al. reported decreased Treg frequency in AD and MS patients of a similar pattern [174] suggesting common roles of impaired Treg immunological tolerance in both the diseases. Dansokho et al. demonstrated that peripheral Treg depletion accelerated cognitive impairment in AD mice without affecting amyloid deposition. Such early cognitive impairment was linked with microglia activation and altered diseaserelated gene expression profile [175]. Beak et al. showed that Treg depletion markedly increased amyloid plaque deposition and aggravated spatial learning abilities in 3xTg-AD mice. Adoptive transfer of Tregs significantly corrected cognitive deficits and reduced amyloid burden, while Teff transplantation worsened the behavioral outcome in recipients [23]. Dansokho et al. and Beak et al. reported detrimental effects of Treg depletion on memory and microglial function [23, 175]. In contrast, Baruch et al. reported amyloid clearance and improved cognition following Treg depletion in AD mice [173]. The major difference amongst studies that earlier studies were performed using early age diseased mice when amyloid deposition and gliosis have just started; while in the later study, researchers depleted Treg at an intermittent disease stage when cerebral $A \beta$ plaque and gliosis have significantly developed. Additionally, different strategies of Treg depletion were employed in studies. Importantly, Baruch et al. results suggested that transient Treg depletion promotes late recruitment of immunoregulatory Tregs and monocyte-derived macrophages, which play a role in mitigating neuroinflammatory responses [173]. In another study human umbilical cordderived mesenchymal stem cells (hUC-MSCs) treatment of Tregs from APP/PS1 mice restored their immunosuppressive function and their transplantation significantly reduced $A \beta$ plaque deposition and corrected cognitive impairments in recipient mice. The results were accomplished by reduced IFN- $\gamma$, increased TGF- $\beta 1$ and IL-10 
levels in the periphery, and attenuated brain microgliosis [176]. Together, these reports support neuroprotective capabilities of systemic Tregs in AD pathogenesis attributed to their cytokine dependent direct effects or indirect effects on CNS innate immune cell function.

Therapeutic approaches to boost peripheral Treg frequency and function can be harnessed for effective $\mathrm{AD}$ treatment. For instance, amplification of Tregs with low dose IL-2 increased number of plaque-associated microglia, reduced A $\beta$ load, and restored cognition in APP/ PS1 mice [175]. Later, reduced IL-2 levels were observed in the hippocampal biopsies of $\mathrm{AD}$ patients. A single AAV-IL2 injection induced prolonged Treg expansion and activation in both periphery and brain of APP/PS1 mice. In the hippocampus, IL-2 activated astrocytes surrounding amyloid plaques and improved synaptic plasticity to recover memory deficits [177]. Together, studies propose adjunct IL-2 in immune modulatory therapeutic regimens of $\mathrm{AD}$ patients to boost Treg frequency and function. Treatment of bee venom phospholipase A2 (bvPLA2) significantly improved cognitive function and reduced hippocampal $A \beta$ deposits in 3xTg mice. Effects were attributed to Treg induction because Treg depletion using anti-CD25 antibody abrogated bvPLA2 neuroprotective effects [178]. Fingolimod reduced amyloid burden and microglia activation in 5xFAD mice by promoting Tregs entry inside the CNS with simultaneously attenuating other Teffs entry by sequestering them into the peripheral lymph nodes [179]. Similar antiinflammatory mechanism of fingolimod has been reported in MS patients [145] and a traumatic brain injury model [180]. Recently, our laboratory demonstrated immunomodulatory effects of GM-CSF. GM-CSF treatment induced Treg frequency in the periphery that ameliorated amyloid burden and microglia activation in APP/PS1 mice brains. Improved behavioral function was also attributed to its Treg effects [17]. Likewise, a recent phase II clinical trial utilizing sargramostim [Leukine ${ }^{\circ}$, recombinant human GM-CSF (rhGM-CSF)] demonstrated significant changes in mini-mental state examination (MMSE) scores in mild-to-moderate AD patients [181]. Although the study did not evaluate Treg populations, improved memory outcome in AD patients might be attributed to GM-CSF Treg effects that can be studied in future. The overall differential effects of Teffs and Tregs in AD pathogenesis are illustrated in Fig. 3.

\section{Parkinson's disease (PD)}

Following AD, PD is the second most common neurodegenerative disease associated with progressive loss of motor function. Available treatments affect symptoms, but do not alter disease progression. PD is classically characterized by the loss of dopaminergic neurons within the substantia nigra (SN) along with their projections into the striatum resulting in insufficient dopamine release that leads to progressive motor impairment. The remaining surviving neurons often contain intracellular inclusions, called Lewy bodies. These are composed of modified $\alpha$-synuclein and are associated with microgliosis which serve as a key pathological hallmark of the disease (Fig. 3) evidenced only after postmortem analysis of the patient brain [3]. Considerable evidence shows that infiltration of peripheral immune cells and microglial activation are key mediators of the persistent neuroinflammatory responses in PD that subsequently lead to dopaminergic neuronal cell death [13]. Studies have demonstrated the presence of CD4+ and $\mathrm{CD} 8+\mathrm{T}$ cells in the SN of post-mortem brains from PD patients. Similarly, T lymphocyte infiltration was observed in the MPTP mouse model of PD, where T cells were associated with nigrostriatal neuronal cell death [1, 13, 29, 182]. CNS infiltration of T lymphocytes occurs following their early peripheral activation; therefore, altered T lymphocyte populations in PD patients' blood could likely be considered for early disease diagnosis. Several studies have revealed alterations in peripheral immune subsets in PD patients [24, 183, 184]. Previously, our laboratory demonstrated the association of motor severity with peripheral $\mathrm{T}$ lymphocytes in $\mathrm{PD}$ patients; wherein, increased effector memory $\mathrm{T}$ cell (Teff) frequency was associated with impaired motor function [118]. Although no differences in Treg and Teff frequencies between PD patients and caregivers were observed, the immunosuppressive capability of Tregs was compromised in PD patients and highlights disease associated functional Treg deficits. Baba et al. reported decreased CD4+/CD8+ $\mathrm{T}$ cell ratio and $\mathrm{CD} 4+\mathrm{CD} 25+$ Treg frequency in PD patients compared to healthy controls. In PD patients, a phenotypic shift towards Th1-type immune responses was observed due to IFN- $\gamma$ producing Th1 cells were significantly upregulated compared to IL4 producing Th2 cells [185]. In this study, patients treated with levodopa showed significantly lower number of different $\mathrm{T}$ cell subsets compared to controls. However, Bas et al. reported a similar reduction in lymphocyte count of PD patients irrespective of Levodopa treatment [186] suggesting that lymphocyte alterations are not directly dependent on dopaminergic treatment. Other studies showed elevated frequencies of Th1 [184] and Th17 [187] Teffs in the peripheral blood of PD patients with concurrent occurrence of T lymphocytes in postmortem brain specimens [13]. Chen et al. suggested the active role of peripheral immune system in the progression of PD. Using PD patients' blood analyses, authors concluded the presence of increased proportions of Th1 and Th17 cells with decreased Th2 and Treg subtypes. The elevated Th1/Th2 ratio was associated with motor function scores determined by Unified 
Parkinson's Disease Rating Scale-III (UPDRS-III), but not with elevated Th17/Treg ratio. This may be because UPDRS-III may not fully reflect the disease severity [183]. In cross-sectional studies, Kustrimovic et al. observed reduced circulating CD4+ T cells in PD patients that included Th2, Th17, and Treg populations [184]. Isolated naïve $\mathrm{CD} 4+\mathrm{T}$ cells preferentially differentiated towards the Th1 lineage in both PD patients (drug-naïve and dopaminergic drug treated) further verified that current symptomatic treatments are unable to modulate ongoing peripheral adaptive immune alterations. Overall, studies suggest effector adaptive immune alterations are operative over the disease course and may serve as novel biomarkers in PD diagnosis. In the brain, dopaminergic neuronal cell death releases modified protein $\alpha$ synuclein into the extraneuronal environment causing activation of resident microglia and subsequent induction of antigen-specific Teff populations in the secondary lymphoid organs $[2,3]$. Thus, it is likely that diseasecausing Teffs are initially activated in the periphery where they undergo clonal differentiation and expansion in order to enter the PD brain.

Tregs can be harnessed to attenuate such effector immune responses to maintain central and peripheral immune tolerance and diminish neuroinflammation [188]. Tregs not only suppress effector immune responses but also transform neurodestructive Th1 and Th17 responses into neuroprotective ones [1], suggesting immunomodulator potential of Tregs in PD (Fig. 3). Depletion of Tregs can exacerbate neuroinflammation in the MPTP mouse model of PD [189] suggesting their direct role in neuroprotection. Direct protective effects of Tregs on MPTP-intoxicated primary ventral mesencephalic dopaminergic neurons was demonstrated. It was shown that CD47-SIRPA interactions was the mechanism independent of Treg associated TGF- $\beta 1$ and IL-10 [120]. Interaction of CD47 on Treg with SIRPA on dopaminergic neuronal cell activated the neuronal Rac1/ Akt signaling pathway to mediate the observed neuroprotection. Previously, our own laboratory demonstrated that adoptive transfer of CD4+ $\mathrm{T}$ cells isolated from copolymer-1 (glatiramer acetate) immunized mice to MPTP-intoxicated recipient mice significantly protected the nigrostriatal dopaminergic system by attenuating microglial activation [29]. The results were likely attributed to the Treg responses as copolymer- 1 is a potent inducer of this cell type [28, 190, 191]. Later, our laboratory adoptively transferred CD3-activated CD4+CD25+ Tregs into MPTP-intoxicated mice. A dose-dependent neuroprotective response was observed with concomitant suppression of microglia activation, leading to increased survival of dopaminergic neurons in the SN [22]. Adoptive transfer of $\mathrm{T}$ cells from mice imminzed with nitrated alpha-synuclein (N- $\alpha$-synuclein $\}$ to MPTP- treated mice exacerbated neuroinflammation and nigrostriatal degeneration, which was attributed to Th1 and Th17 mediated immune responses with parallel Treg dysfunction $[1,16]$. Adoptive transfer of natural Tregs or Tregs induced by VIP significantly attenuated microglial inflammatory responses leading to robust nigrostriatal neuroprotection in MPTP mice. Thus, we described the therapeutic implications of peripheral Treg induction in PD. Later to overcome the limitations of native VIP for clinical application, we developed a selective VIP receptor 2 (VIPR2) agonist that reduced IL-17A, IFN- $\gamma$, and IL- 6 release and increased GM-CSF transcripts in CD4+ T cells, induced phenotypic shift towards Treg [25]. Our laboratory also has used recombinant GM-CSF to increase Treg numbers and function in PD patients and animal models. In the MPTP mice model, GM-CSF induced Treg number and function leading to nigral dopaminergic neuroprotection and corrected microglia responses. The results were confirmed when adoptive transfer of GM-CSF-induced Tregs showed nigral neuroprotection in recipient MPTP mice [26]. Moreover, in a phase I clinical trial, sargramostim (rhGM-CSF) treatment improved UPDRS-III scores and magnetoencephalography-recorded cortical motor activities in PD patients. GM-CSF treatment increased Treg frequency and function that contributed protective effects in patients [24]. As discussed, both VIP and GM-CSF are potent inducers of tolerogenic DCs that could be a possible mechanism of Treg induction $[95,96]$. Direct neuroprotective effects of GM-CSF were also reported. GM-CSF protected MPP+ treated PC12 cells and mouse primary mesencephalic neurons in vitro by modulating apoptosis related proteins. The results were confirmed in vivo where GM-CSF protected dopaminergic neurons in the $\mathrm{SN}$ and improved locomotor activity in MPTP mice [192]. Overall studies suggest direct as well as indirect neuroprotective mechanism of GM-CSF in PD. Ginsenoside Rg1 treatment abrogated peripheral and central inflammation in MPTP mice. Rg1 protected dopaminergic neurons by inhibiting microglia activation and $\mathrm{CD} 3+\mathrm{T}$ cell infiltration into the substantia nigra pars compacta (SNpc). In the periphery, Rg1 increased FOXP3+ Tregs while reducing inflammatory cytokines TNF- $\alpha$, IFN- $\gamma$, IL- 6 , and IL-1 $\beta$ [193]. Although the anti-inflammatory property of Rg1 has been reported in the neurological diseases [194], its immunoprotective mechanisms seek further investigation. bvPLA2 can also induce peripheral Tregs to promote dopaminergic neuronal survival in MPTP mice. The protective effects were associated with microglia deactivation and limited $\mathrm{CD} 4+\mathrm{T}$ cell infiltration into the brain. Interestingly, the protective effects of bvPLA2 were reversed upon depletion of Tregs. bvPLA2 directly bound to CD206 on DCs and constitutively promoted 
the secretion of PGE2 that via PGE2 (EP2) receptor signaling facilitated Treg differentiation from FOXP3CD4+ T cells [195]. The finding further highlights the key role of DCs in immunoprotection by transforming Tregs from Teffs. Taken together, these findings suggest that therapeutic approaches to amplify peripheral Treg frequency and function would be promising in clinics over conventional symptomatic treatments. Different immunomodulators with the ability to increase peripheral Treg frequency and function and their downstream neuroprotective effects are summarized in Table 1.

\section{Amyotrophic lateral sclerosis (ALS)}

ALS is a progressive neurodegenerative disease with unknown etiology primarily affecting upper and lower motor neurons in the motor cortex, brain stem, and spinal cord. ALS pathogenesis mechanisms include glutamate excitotoxicity and dominant mutations in the gene for superoxide dismutase 1 (SOD1) leading to mitochondrial toxicity. This facilitates recruitment of astrocyte and microglia cells surrounding damaged motor neurons in the spinal cord and brain, triggering oxidative stress by releasing ROS and other proinflammatory mediators to orchestrate motor neurodegeneration (Fig. 4) [213, 214]. ALS pathogenesis consists of mainly two stages: an early, slow progressive neuroprotective stage and later, a rapidly progressing neurotoxic stage associated with anti-inflammatory and proinflammatory immune responses, respectively $[213,215]$. Neuroinflammation is a common feature among multifactorial disease etiologies characterized by the alterations in innate and adaptive immune responses in both periphery and CNS $[214,215]$. Studies over the past decades have demonstrated the infiltration of peripheral $\mathrm{T}$ lymphocytes and APCs that secrete a variety of cytokines in the spinal cord and brain of ALS patients. Troost et al. first identified substantial infiltration of $\mathrm{T}$ cells (including CD4+ and CD8+) and macrophages in the corticospinal tracts and anterior horn of the spinal cord in ALS patients [216]. Such infiltrations were observed secondary to spinal cord atrophy suggesting activation of peripheral adaptive immune system follows initial neurodegeneration. Later, Kawamata et al. identified CD4+ and CD8+ T lymphocyte migration along the capillaries and venules of the pre-central gyrus in ALS patients that extended up to the parenchyma exhibiting neuronal damage [217]. The study further confirmed autoimmune alterations inside the brain and spinal cord of ALS patients secondary to neuronal demise. Engelhardt et al. found perivascular and intraparenchymal $\mathrm{T}$ lymphocyte infiltration in the corticospinal tract and ventral horns of the spinal cord during autopsies of ALS patients [218]. Graves et al. reported perivascular infiltration of $\mathrm{T}$ lymphocytes along with macrophages and mast cells in the spinal cord and brain of ALS patients [219] suggesting both adaptive and innate immune systems are activated over the disease course. Similar CD4+ and CD8+ T lymphocyte infiltration was observed and associated with microglia activation in the brains of ALS mice [220]. Studies suggest that effector immune responses are extended into the CNS from the periphery where they contribute to systemic inflammation. Saresella et al. demonstrated increased expression of both Th1 and Th17 Teffs with reduced frequency of IL-10 and TGF- $\beta$ expressing Tregs in the peripheral blood of ALS patients comparable to MS patients [221] suggesting common systemic inflammatory immune responses between ALS and MS. Rentzos et al. identified elevated frequency of CTLs and NK T cells with simultaneous reduction of Tregs in peripheral blood of ALS patients where Treg frequency negatively correlated with the disease progression rate [222], suggesting the indisputable role of impaired Treg suppressive circuit in ALS immune activation.

Tregs increase during the early slow progressive disease stage, protecting M2 microglia while decreasing during the later rapidly accelerating disease stage [215]. Beers et al. demonstrated that passive transfer of endogenous Tregs from early disease staged mutant SOD1 (mSOD1) mice into advanced disease mice sustained IL4 expression and M2 microglia phenotype leading to extended stable disease stage in recipients. The results were extended to ALS patients and showed reduced Treg frequency in rapidly progressing patients [198]. Thus, the study suggested a beneficial role of expanding peripheral Tregs to suppress toxic neuroinflammation in the CNS of ALS patients. During the rapidly progressing disease phase, decreased peripheral Treg frequency in mSOD mice paralleled with increased proliferation of Teff, opposite to early slow disease phase. Therefore, systemic transplantation of Tregs isolated during the slow phase suppressed Teffs and microglial neurotoxicity during rapid progressive phase [21]. Decreased Treg number and FOXP3 expression were found in rapidly progressing ALS patients suggesting functional Treg deficits over disease period as FOXP3 transcription factor is a key determinant of Treg immunosuppressive function. The expression of TGF- $\beta$, IL- 4 , and GATA-3, a Th2 transcription factor, was also reduced in rapidly progressing ALS patients [223]. In line with earlier reports, recently it was demonstrated that Tregs isolated from ALS patients' blood were less effective in suppressing responder $\mathrm{T}$ cell proliferation. Although both slowly and rapidly progressing ALS patients showed Treg dysfunction, Tregs from rapidly progressing patients were affected to a greater extent [224]. Epigenetically, the methylation of the Treg-specific demethylated region (TSDR) was also greater in ALS patients compared to the healthy controls. The report further suggested 
Table 1 Peripheral Treg expansion for disease combating neuroprotection in different neurodegenerative animal models

\begin{tabular}{|c|c|c|c|}
\hline Treg expansion & Disease & $\begin{array}{l}\text { Experimental } \\
\text { model }\end{array}$ & Effects \\
\hline \multirow[t]{5}{*}{ Adoptive transfer } & MS & EAE & Resistance to reinduction of EAE [196]. Mice are disease-free [197]. \\
\hline & $A D$ & $3 \times \operatorname{Tg}$ & Reduced A $\beta$ plaque deposition and improved behavior [23] \\
\hline & PD & MPTP & $\begin{array}{l}\text { Attenuated Th17 neurodestructive and microglial inflammatory responses and induced } \\
\text { nigrostriatal protection [1] }\end{array}$ \\
\hline & ALS & $\begin{array}{l}\mathrm{mSOD} 1 / \mathrm{RAG}_{2}^{-/-} \\
\mathrm{mSOD} 1^{\mathrm{G} 93}\end{array}$ & Tregs isolated from disease mice prolonged survival $[21,198,199]$ \\
\hline & Stroke & MCAO & $\begin{array}{l}\text { Reduced brain infarction [200], attenuated inflammation and BBB damage [201]. } \\
\text { Exerted early neuroprotection without entering the brain [202]. Promotion of } \\
\text { neurogenesis [203] and remyelination [18]. }\end{array}$ \\
\hline \multirow[t]{2}{*}{ Low dose IL-2 } & MS & EAE & Pre-treatment only attenuated EAE [204]. \\
\hline & $A D$ & $\begin{array}{l}\text { APP/PS1, APP/ } \\
\text { PS1 } \triangle \mathrm{E} 9\end{array}$ & $\begin{array}{l}\text { Restored cognitive function, increased number of plaque associated microglia [175] } \\
\text { and astrocytes [177] }\end{array}$ \\
\hline \multirow[t]{2}{*}{ GM-CSF } & $A D$ & APP/PS1 & $\begin{array}{l}\text { Increased } A \beta \text { clearance and improved cognition. Recruitment of microglia surrounding } \\
A \beta \text { plaque, improved synaptic plasticity and neurogenesis [17] }\end{array}$ \\
\hline & PD & MPTP & $\begin{array}{l}\text { Protected tyrosine hydroxylase immunoreactive }(\mathrm{TH}+) \text { neurons in } \mathrm{SN} \text {, attenuated } \\
\text { microglial activation and improved motor functions }[26,192]\end{array}$ \\
\hline \multirow{2}{*}{$\begin{array}{l}\text { Vasoactive intestinal } \\
\text { peptide (VIP) }\end{array}$} & MS & EAE & Inhibited encephalitogenic T cell activation and slowed disease [144] \\
\hline & PD & MPTP & $\begin{array}{l}\text { Attenuated microglial activation and spared TH+neurons in SN. Phenotypic shift of } \\
\text { effector cells to Treg was observed [25] }\end{array}$ \\
\hline \multirow[t]{2}{*}{ Fingolimod } & MS & EAE & $\begin{array}{l}\text { Inhibited peripheral Teffs entry inside the CNS by sequestering them into lymph nodes } \\
\text { but allowed Tregs entry }[145,146]\end{array}$ \\
\hline & $A D$ & $5 \times F A D$ & $\begin{array}{l}\text { Decreased amyloid plaque and microglia activation and promoted anti-inflammatory } \\
\text { neuroprotective responses [179] }\end{array}$ \\
\hline \multirow[t]{4}{*}{$\begin{array}{l}\text { IL-2/IL-2 antibody } \\
\text { complex (IL-2/IL-2Ab) }\end{array}$} & MS & EAE & $\begin{array}{l}\text { Development of resistance to induction of EAE [205] and reduced disease severity } \\
\text { [206] }\end{array}$ \\
\hline & ALS & $\mathrm{mSOD} 1^{\mathrm{G} 93 \mathrm{~A}}$ & Slowed down disease progression rate and increased survival period [207] \\
\hline & Stroke & MCAO & $\begin{array}{l}\text { Early Treg protective effects independent to their brain penetration by suppressing } \\
\text { peripheral Teffs. Also attenuated central neuroinflammation and protected against } \\
\text { brain injury [208]. }\end{array}$ \\
\hline & $\begin{array}{l}\text { Traumatic brain } \\
\text { injury (TBI) }\end{array}$ & $\begin{array}{l}\text { controlled cortical } \\
\text { impact (CCl) }\end{array}$ & $\begin{array}{l}\text { Attenuated neutrophil infiltration and inflammation leads to improved neurological } \\
\text { recovery [209]. }\end{array}$ \\
\hline \multirow[t]{2}{*}{$\begin{array}{l}\text { Bee venom } \\
\text { phospholipase A2 }\end{array}$} & $A D$ & $3 \times \operatorname{Tg}$ & $\begin{array}{l}\text { Decreased } A \beta \text { deposits in hippocampus and enhanced cognitive function. Microglia } \\
\text { deactivation and reduced } C D 4+T \text { cell infiltration }[178,210]\end{array}$ \\
\hline & PD & MPTP & Induced microglia deactivation and attenuated CD4+ T cell infiltration $[189,195,211]$ \\
\hline Ginsenoside Rg1 & PD & MPTP & Inhibited microglia activation and CD3+ T cell infiltration [193] \\
\hline $\begin{array}{l}\text { Intravenous } \\
\text { immunoglobulin (IVlg) }\end{array}$ & MS & EAE & $\begin{array}{l}\text { Prevented CNS infiltration of Teffs and almost completely protected mice from EAE } \\
\text { [143] }\end{array}$ \\
\hline Atorvastatin & Stroke & MCAO & Prevented infarct and glia activation [212] \\
\hline
\end{tabular}

functional Treg deficit as a key etiological factor in ALS. In vitro expanded ALS Tregs regained suppressive activity suggesting that passive transfer of autologous expanded Tregs might slow down disease progression. Supporting that possibility, infusion of ex vivo expanded autologous Tregs was found safe and well-tolerated in ALS patients associated with slowed disease progression rates during both early and late stages [225]. Therefore, therapies to expand Tregs can be developed for the potential treatment of ALS to suppress peripheral as well as CNS inflammatory immune responses. Recently, treatment of IL-2/IL-2-antibody complex (IL-2c) amplified endogenous Tregs in SOD93A mice. Treg expansion significantly slowed disease progression and increased survival time in mice. Treg expansion was associated with motor neuron function restoration and microglia/astrocyte inactivation with concomitant upregulation of FOXP3 and Gata3 in the spinal cord and sciatic nerve [207]. Several clinical attempts are underway to amplify Treg frequency in ALS patients. The phase II trial, known as MIROCALS, is currently ongoing to assess safety and efficacy of low-dose IL-2 as a Treg enhancer for controlling neuroinflammation in newly diagnosed ALS patients (NCT0303 9673). Another phase II clinical trial to determine safety 


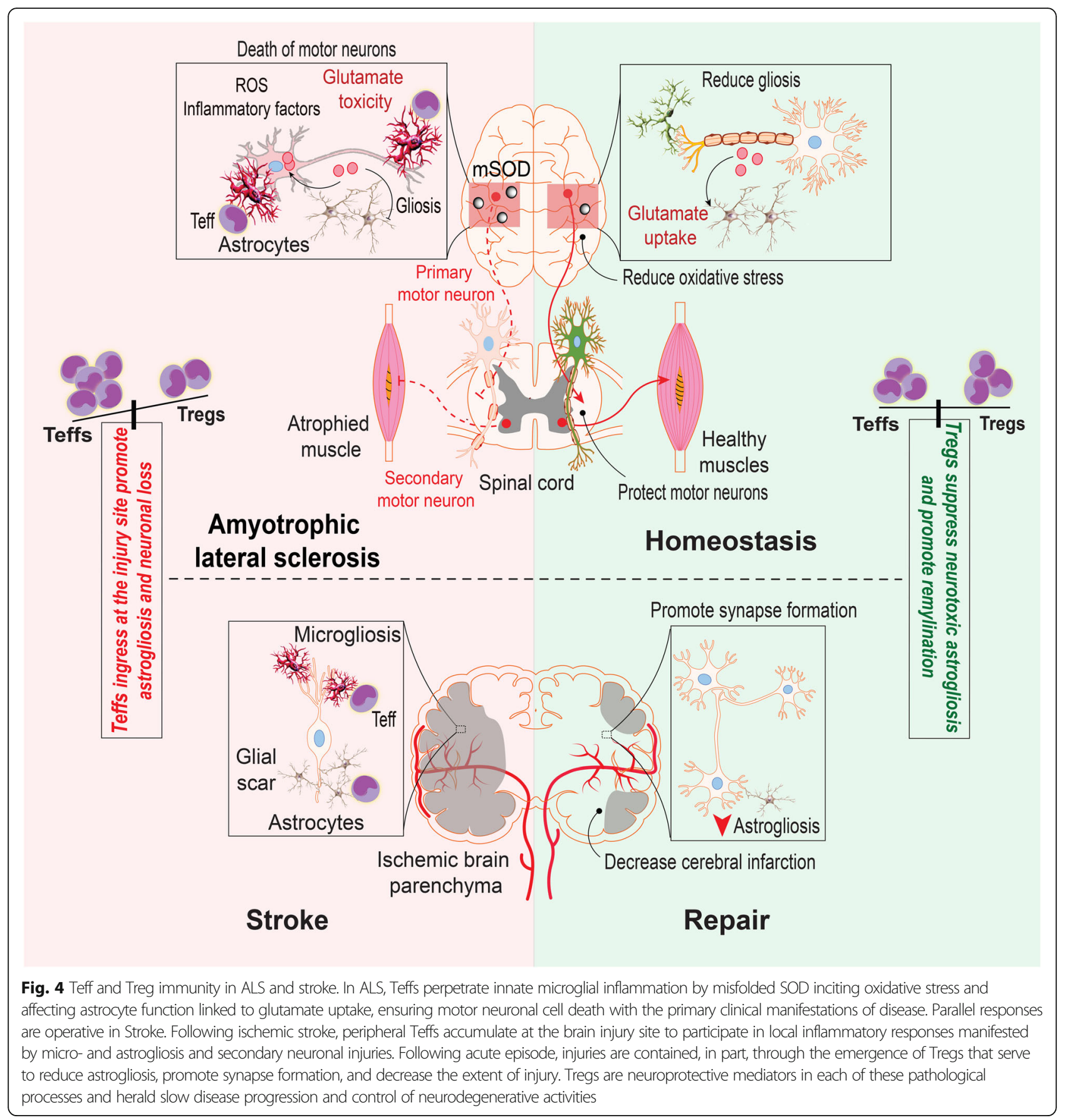

and efficacy of dimethyl fumarate (Tecfidera) in patients with ALS is underway (ACTRN12618000534280). Dimethyl fumarate is currently used for the treatment of relapsing MS to increase Treg frequency and reduce inflammatory responses. Therefore, investigators are hoping to slow ALS progression by targeting the same pathway. Another candidate, fingolimod, reduces inflammation in ALS by sequestering $\mathrm{T}$ cells inside the lymph nodes, therefore inhibits T cell CNS entry. In a Phase II clinical trial, fingolimod was safe and sequestered lymphocytes but unfortunately sequestration also included Tregs [226]. Although, lower doses of fingolimod in mice kept Tregs in the circulation, this dose is not safe in humans due to potential heart complications [227]. Clinical studies to expand peripheral Tregs for the potential treatment of ALS are summarized in Table 2. Overall, as illustrated in Fig. 4, distinct effects of Teffs and Tregs determine ALS pathogenesis progression rate. 
Table 2 Clinical studies to increase Treg frequency and function in different neurodegenerative disorders

\begin{tabular}{|c|c|c|c|c|c|}
\hline $\begin{array}{l}\text { Clinical } \\
\text { Phase }\end{array}$ & Intervention & Condition & Status & Trial identifier & Outcome \\
\hline$|\&| \mid$ & Autologous Treg (GB301) & $A D$ & $\begin{array}{l}\text { Not yet } \\
\text { recruiting }\end{array}$ & NCT03865017 & - \\
\hline$\|$ & Sargramostim (rhGM-CSF) & $A D$ & Completed & NCT01409915 & Improved memory function [181] \\
\hline- & Dimethyl fumarate (Tecfidera) & MS & Approved & NCT02461069 & $\begin{array}{l}\text { Approved as first line } \\
\text { monotherapy }\end{array}$ \\
\hline- & Fingolimod (FTY720) & MS & Approved & NCT00333138 & First orally approved therapy \\
\hline$\|$ & Low dose IL-2 & MS & Recruiting & NCT02424396 & - \\
\hline NA & Vitamin D3 & MS & Completed & NCT00940719 & Unaffected Tregs [228] \\
\hline II (WIRMS) & Hookworm larvae & MS & Completed & NCT01470521 & - \\
\hline । & Sargramostim (rhGM-CSF) & PD & Completed & NCT01882010 & Improved motor function [24] \\
\hline । & Sargramostim (rhGM-CSF) & PD & Active & NCT03790670 & - \\
\hline । & Autologous Treg with IL-2 & ALS & Completed & NCT03241784 & Slow disease progression [225] \\
\hline$\|$ & Autologous Treg with IL-2 & ALS & Recruiting & NCT04055623 & - \\
\hline $\begin{array}{l}\text { "I } \\
\text { (MIROCALS) }\end{array}$ & $\begin{array}{l}\text { Riluzole with IL2 and } 5 \% \text { glucose water } \\
\text { solution }\end{array}$ & ALS & Recruiting & NCT03039673 & - \\
\hline ॥ (TEALS) & Dimethyl fumarate (Tecfidera) & ALS & $\begin{array}{l}\text { Not yet } \\
\text { recruiting }\end{array}$ & $\begin{array}{l}\text { ACTR } \\
\text { N12618000534280 }\end{array}$ & - \\
\hline
\end{tabular}

\section{Stroke}

Stroke is the leading cause of death and disability worldwide. Ischemic stroke is the most common type of stroke associated with cerebral ischemia and inflammatory immune responses that induce long-term secondary brain injury after initial primary brain injury [229]. Reactive astrocytes are the most characteristic feature of ischemic stroke resulting in glial scar formation at the site of tissue injury (Fig. 4). Although the exact etiology is still not clear, inflammation is considered to play a significant role in the pathogenesis of ischemic stroke that arises after apoptotic cell death of the ischemic tissue [230]. Understanding post-stroke inflammatory responses will enable researchers to understand potential therapeutic targets for stroke management and functional recovery of the affected brain. Involvement of $\mathrm{T}$ cell subsets in inflammation-mediated ischemic brain injury has been profoundly recognized. Following ischemic brain injury, $\mathrm{T}$ lymphocytes become activated, extravasate into the brain parenchyma, and accumulate in the necrotic core and ischemic penumbra [231]. Both human and animal studies showed infiltration of innate immune cells, neutrophils [232], macrophages [233], and adaptive immune $\mathrm{T}$ lymphocytes [234, 235] that release cytokines in response to debris from the necrotic tissue and signals from resident innate immune cells in the ischemic brain. Intracellular components from the necrotic tissue such as HMGB1, ATP, NAD and HSP70 among others serve as antigenic peptides that interact with the TLRs on infiltrating and resident innate immune cells to build a strong pro-inflammatory environment [236]. Pro-inflammatory mediators released from innate immune cells and infiltrated $\mathrm{T}$ lymphocytes orchestrate secondary injuries in the affected brain [237, 238]. It was shown that increased IL-17 expression colocalized with the neuroglia cells in the rat brain following permanent middle cerebral artery occlusion (MCAO) after an hour after injury. For the first time, similar IL-17 expression was observed in human ischemic brains that peaked slightly earlier suggesting the pathogenic role of IL-17 secreting pro-inflammatory cells in disease progression [239]. Later, increased infiltration of IL-23-secreting macrophages and IL-17expressing $\mathrm{T}$ lymphocytes was shown in mouse brains following ischemia-reperfusion injury. To determine the functional significance of cytokines, cytokine-deficient mice that were genetically deficient (knockout) in IL-17, IL-23p19 and IFN- $\gamma$ were studied. A significant reduction in infarct size was seen in IL-23p19 and IL-17 knockout mice but not in IFN- $\gamma$ knockout mice. These data helped to confirm the roles of IL-23 and IL-17 in ischemic inflammatory responses [240]. Increased CNS infiltration of Teffs occurs after initial peripheral adaptive immune activation. Clinical studies have shown elevated frequency of peripherals Th17 cells in patients that corelated to the ischemic brain area [239]. A similar increase in peripheral Th17 cell differentiation with concomitant increase in pro-inflammatory cytokines IL$17 \mathrm{~A}$, TNF- $\alpha$, IL- 6 and IL- $1 \beta$ was observed after MCAO in mice [241]. Therefore, early peripheral Teff responses are involved in worsened later ischemic stroke outcomes. Luo et al. observed increased infiltration of both Th1 and Th17 cells in the ischemic core of the mouse brain following MCAO. Treatment with IL-33, an IL-1 
family member, significantly inhibited neuroinflammation by an immune-shift of pro-inflammatory Th1 cells towards anti-inflammatory Th2 cells and suppressed Th17-mediated immune responses [241] suggesting candidates exhibiting the potential to transform effector immune responses into regulatory phenotype can be harnessed for therapeutic gain. Infiltrating Teffs can be detected for as long as 30 days post infarction in the brain parenchyma [242]. Together, the above reports suggest an indispensable role of Teffs in the ischemic neuroinflammation and Th1 and Th17 cells serve as primary invaders to the ischemic parenchyma from the periphery.

The role of immunosuppressive Tregs in the pathogenesis of stroke remains not well-defined. Few Tregs are observed early after stroke onset, but their count increases in later disease phase that last up to a month after injury. However, CD4+CD25+ Treg depletion did not affected neurological outcomes [243] and may be due to larger infarct size. In another study, selective depletion of Tregs dramatically reduced infarct size and improved neurological function $24 \mathrm{~h}$ after stroke onset, but this protective effect was abrogated at later disease stages [244]. Several studies, however, suggest a beneficial role of Tregs in stroke pathology. Depletion of FOXP3+ Tregs increased delayed damage and worsened functional outcomes in MCAO mice. Treg depletion also augmented post-ischemic activation of resident and infiltrated immune cells including microglia and TNF- $\alpha$ and IFN- $\gamma$-secreting T cells [245] suggesting an ability of Tregs to suppress effector innate and adaptive immune responses during disease. In another study, Treg depletion completely eliminated neuroprotection afforded by IL-2c in mice [208]. A clinical study also showed a significant reduction of peripheral Teffs and Tregs in patients with acute stroke. Teff decline was linked to stroke-associated infection; whereas, Treg decline was directly associated with stroke onset [246]. Overall, neuroprotective responses offered by Tregs are notable in ischemic stroke. Indeed, adoptive transfer of Tregs during both early and late disease stages markedly reduced infarct volume and improved neurological functions in an ischemic mouse model with other long-term protective effects. Tregs restored disruption of BBB integrity in early disease stage and attenuated cerebral inflammation by affecting peripheral immune cell trafficking [202]. During early disease stage, Tregs can elicit neuroprotective responses without entering brain parenchyma. This is due to the effects on the peripheral effector immune system. By suppressing elevated IL- 6 and TNF- $\alpha$ levels in the blood, Tregs abrogated systemic inflammatory immune responses [201]. Recently, CCR5 was found to be essential for trafficking Tregs to the injury site as CCR5 -/- Tregs failed to attenuate brain infarction or neurological deficits. In contrast, CCR5-inducing Tregs inhibited BBB impairment and abrogated peripheral $\mathrm{T}$ lymphocyte trafficking [122]. Therefore, therapeutic approaches to expand peripheral Tregs could be advantageous to suppress both peripheral and central immune activation in stroke. Boosting Treg immunosuppressive capacity and IL-10 expression using HDACi reduced infarct volume, behavioral deficits, and cerebral neuroinflammation in a cortical ischemia mouse model [27]. Beneficial effect of IL-2c on Treg expansion was shown in a rodent model of ischemic stroke. In the periphery, IL-2c elevated Treg numbers in blood, spleen, and lymph nodes and boosted their Teff suppressive function by enhancing expression of CD39 and CD73. In the brain, elevated Tregs reduced infarct volume and neuroinflammation and improved sensorimotor functions [208]. Figure 4 illustrates the different roles of Teffs and Tregs in the pathogenesis of stroke by emphasizing the neuroprotective Treg role.

\section{HIV-1 associated neurocognitive disorders (HAND)}

With antiretroviral therapy (ART), the life expectancy of HIV-1 infected people has increased significantly. However, end organ disease has continued almost unabated with low level infection inciting, for example, HIV-1 associated neurocognitive disorders (HAND). Up to 50\% of ART-treated HIV-1 infected people develop HAND [196]. The disease spectrum includes asymptomatic neurocognitive impairment, mild neurocognitive disorder, and HIV-associated dementia [197]. Increasing evidence demonstrates that a low $\mathrm{CD} 4+/ \mathrm{CD} 8+$ ratio is associated with an increased risk of disease in virally suppressed infected individuals $[199,200]$. Indeed, reduced $C D 4+/$ CD8+ ratio in both peripheral blood and CSF correlate with the neurocognitive impairment scores of ARTtreated HIV patients. These data support the idea that HIV patients with low CD4+ T cell counts are at greater risk of developing HAND compared to patients with higher cell counts. Additional analysis of T cell subsets revealed that reduced frequency of naive $\mathrm{CD} 4+$ and $\mathrm{CD} 8+\mathrm{T}$ cells were associated with increased frequency of effector memory CD4+ and CD8+ T cells in HIV patients compared to healthy controls [203]. Reduced Treg frequency has been reported in HIV-infected individuals with low CD4+ T cell counts [204]. Others demonstrated increased frequency of Tregs with reduced HIVspecific immunosuppressive functions in patients with low CD4+ T cells on ART compared to patients left untreated [205]. High levels of circulating Th17 cells were observed in HIV patients with poor CD4+ reconstitution despite being on ART treatment. Interestingly, this occurred with increased Treg frequency and immune activation [206]. Other studies reported no differences in expression of both CD4+CD25+ and FOXP3+ Tregs in HIV patients before and after ART. However, HIV patients 
had higher Treg percentages compared to healthy controls [209]. Despite such discrepancies, most studies reported increased Treg frequency among different $\mathrm{CD} 4+\mathrm{T}$ cell subsets during HIV infection irrespective of ART [210-212].

The consequences of increased Treg numbers during HIV could be either beneficial by abrogating generalized $\mathrm{T}$ cell activation preserving $\mathrm{CD} 4+\mathrm{T}$ cell counts or detrimental by weakening antiviral immune responses and affecting viral persistence [212]. Previously, neuromodulatory effects of Tregs were demonstrated. Intracranial injection of human HIV-infected murine bone marrowderived macrophages induced focal encephalitis with robust micro- and astrogliosis in mice. Adoptive transfer of Tregs significantly attenuated neuroinflammation and led to neuroprotective responses [228]. A subsequent study demonstrated that Tregs migrated to the virus-induced neuroinflammatory sites and modulated microglial responses in HIV-1 encephalitis [247]. Tregs can kill HIV-1 infected macrophages as well as transform them from a neurodestructive to a neuroprotective phenotype [248]. Tregs suppress HIV-1 infection in CD4+ T cells by cell contact [249]. Suppression of HIV-specific responses occur throughout the course of HIV infection are attributed to lymphoid Tregs [250]. Notably, Tregs present in newborns from HIV-infected mothers can escape infection. This suggests a potential role of Treg immunomodulation in mother-to-child HIV transmission [251]. These reports support the beneficial role of Tregs in infection by suppressing HIV-specific immune responses. In contrast, several studies suggest a detrimental role of Tregs in HIV. In one, IL-2 therapy along with ART was used to expand $\mathrm{CD} 4+\mathrm{T}$ cells in patients beyond what was seen by ART alone. However, despite sustained CD4+ cell numbers, improved clinical outcomes were not seen [252]. The results were attributed to IL-2-mediated Treg induction [253]. Studies suggest that circulating Tregs are now readily susceptible to HIV infection [210, 254]. Immune activation and viral rebound following ART interruption lead to Treg expansion [255]. Studies have shown higher frequency of inducible, intact proviruses in Tregs compared to other CD4+ T cell subsets suggesting Tregs as a key latent HIV reservoir [256-258]. Thus, the role of Tregs in HIV pathogenesis may depend on disease stage.

Overall, affecting peripheral Tregs is a new frontier in neurodegenerative disease treatment. It can control systemic as well as CNS inflammatory processes. A list of candidates capable of expanding peripheral Tregs that have been tested are summarized in Table 1. Clinical trials targeting peripheral Tregs are also summarized and appear in Table 2.

\section{Conclusions}

The brain is no longer considered an immuneprivileged organ. Cross talk between peripheral and
CNS immunity sustains homeostasis. While few $\mathrm{T}$ cells traffic into the CNS they have profound effects on brain function [5]. During infectious, metabolic, degenerative and immune-mediated brain injury, the homeostasis of the brain-immune axis is disturbed with the emergence of effector immune populations and expanded inflammatory activities [11]. Over the past decades, the essential contributions, in health or disease, of the adaptive immune system in brain function has been well-established $[2,13,14]$. The driver affecting the balance between pro-inflammatory Teffs and anti-inflammatory Tregs is the disease itself. Therefore, peripheral emergence of effector immune cells (for disease) and downregulation of regulatory immune cells (protection) may represent an early disease biomarker [3]. To reflect human-specific immune responses operative in brain disorders, our laboratory created a human IL-34 (hIL-34) expressing transgenic

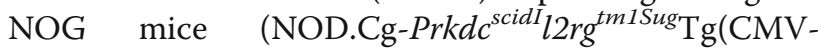
IL34)1/Jic). Upon human hematopoietic stem cell reconstitution, mice develop a human immune system along with human "microglia-like" cells in the brain [259]. Introduction of human AD transgenes or neurotoxins in hIL-34-NOG mice serve to explore human disease-specific immune alterations after exposure to misfolded and aggregated proteins and how immunity can be harnessed to modify disease outcomes. Therapeutic strategies to boost expansions of immunoregulatory, anti-inflammatory, and neuroprotective Tregs are a promising venue to affect neurodegenerative disease progression by sustaining neuroprotective immunity.

\section{Abbreviations}

Aß: Amyloid-beta; AD: Alzheimer's disease; ALS: Amyotrophic lateral sclerosis; APCs: Antigen presenting cells; APP: Amyloid precursor protein;

AQP4: Aquaporin 4; ART: Antiretroviral therapy; BBB: Blood-brain barrier; BDNF: Brain-derived neurotrophic factor; bvPLA2: Bee venom phospholipase A2; CAM: Cell adhesion molecules; CNS: Central nervous system;

CSF: Cerebral spinal fluid; CTLs: Cytotoxic T lymphocytes; CTLA4: Cytotoxic T lymphocyte antigen 4; DC: Dendritic cell; EAE: Experimental autoimmune encephalomyelitis; FOXP3: Forkhead box protein P3; GM-CSF: Granulocytemacrophage colony stimulating factor (GM-CSF); GDNF: Glial cell-derived neurotrophic factor; HAND: HIV-1 associated neurocognitive disorders; HDACi: Histone deacetylase inhibitor; hUC-MSCs: Human umbilical cordderived mesenchymal stem cells; ICAM-1: Intercellular adhesion molecule-1; IFN-Y: Interferon gamma; IGF-1: Insulin-like growth factor 1; IL-2: Interleukin 2; IVlg: Intravenous immunoglobulin; LFA: Leukocyte function-associated antigen; MBP: Myelin basic protein; MCAO: Middle cerebral artery occlusion; MCl: Mild cognitive impairments; MHC: Major histocompatibility complex; MMSE: Mini-mental state examination; MPTP: 1-methyl-4-phenyl-1,2,3,6tetrahydropyridine; N-a-syn: Nitrated alpha synuclein; MS: Multiple sclerosis; NFTs: Neurofibrillary tangles; NK: Natural killer; NLR: Nucleotide-binding oligomerization domain-like receptors; PD: Parkinson's diseases; PLP: Myelin proteolipid protein; PRRs: Pattern recognition receptors; PS1: Presenilin 1; ROS: Reactive oxygen species; SCFA: Short-chain fatty acids; SIRPA: Signal regulatory protein $a$; SN: Substantia nigra; SNpc: Substantia nigra pars compacta; SOD1: Superoxide dismutase 1; TCR: T cell receptor; TGF-

$\beta$ : Transforming growth factor beta; Teffs: Effector T cells; Th: T helper; TLR: Toll-like receptor; TNF: Tumor necrosis factor; Tregs: Regulatory T cells; Tres: Responder T cells; TSDR: Treg-specific demethylated region; UPDRS- 
III: Unified Parkinson's Disease Rating Scale-III; VIP: Vasoactive intestinal peptide

\section{Acknowledgements}

The authors thank Ms. Robin Taylor and Mr. Douglas Meigs for assistance in formatting and editing the manuscript.

\section{Authors' contributions}

JM and HEG wrote the manuscript; JM and BDK created the figures; JM, IKM and HEG conceived and edited the final work; RLM, JH and KEO outlined and structured the review, proofed the text and edited the figures. All authors read and approve the final manuscript.

\section{Funding}

This work was supported by the National Institutes of Health grants P01 DA028555, R01 NS36126, P01 NS31492, P01 MH64570, P01 NS43985, P30 MH062261, R01 AG043540, and 2R01 NS034239; the Frances and Louie Blumkin and Harriet Singer Research Foundations, the Carol Swarts, MD Emerging Neuroscience Research Laboratory; and the Margaret R. Larson Professorship.

\section{Availability of data and materials}

Not applicable.

\section{Ethics approval and consent to participate}

Not applicable.

\section{Consent for publication}

Not applicable.

\section{Competing interests}

The authors declare no conflicts of interest.

\section{Author details}

${ }^{1}$ Department of Pharmacology and Experimental Neuroscience, Center for Neurodegenerative Disorders, University of Nebraska Medical Center, Omaha, NE 68198-5880, USA. ²Department of Radiology, School of Medicine, Stanford University, Palo Alto 94304, USA. ${ }^{3}$ Department of Pharmacy, University of Swabi, Anbar Swabi 23561, Pakistan. ${ }^{4}$ Department of Pathology and Microbiology, University of Nebraska Medical Center, Omaha, NE 68198-5880, USA.

Received: 17 January 2020 Accepted: 13 April 2020

Published online: 05 June 2020

\section{References}

1. Reynolds AD, Stone DK, Hutter JA, Benner EJ, Mosley RL, Gendelman HE. Regulatory T cells attenuate Th17 cell-mediated nigrostriatal dopaminergic neurodegeneration in a model of Parkinson's disease. J Immunol. 2010;184: 2261-71.

2. Anderson KM, Olson KE, Estes KA, Flanagan K, Gendelman HE, Mosley RL. Dual destructive and protective roles of adaptive immunity in neurodegenerative disorders. Trans/ Neurodegener. 2014;3:25.

3. Gendelman HE, Mosley RL. A Perspective on Roles Played by Innate and Adaptive Immunity in the Pathobiology of Neurodegenerative Disorders. J Neuroimmune Pharmacol. 2015;10:645-50.

4. Engelhardt B, Vajkoczy P, Weller RO. The movers and shapers in immune privilege of the CNS. Nat Immunol. 2017;18:123-31.

5. Prinz $M$, Priller J. The role of peripheral immune cells in the CNS in steady state and disease. Nat Neurosci. 2017;20:136-44.

6. Radjavi A, Smirnov I, Kipnis J. Brain antigen-reactive CD4+ T cells are sufficient to support learning behavior in mice with limited $T$ cell repertoire. Brain Behav Immun. 2014;35:58-63.

7. Ziv Y, Avidan H, Pluchino S, Martino G, Schwartz M. Synergy between immune cells and adult neural stem/progenitor cells promotes functional recovery from spinal cord injury. Proc Natl Acad Sci U S A. 2006;103:13174-9.

8. Evans FL, Dittmer M, de la Fuente AG, Fitzgerald DC. Protective and Regenerative Roles of T Cells in Central Nervous System Disorders. Front Immunol. 2019;10:2171.

9. Amor S, Woodroofe MN. Innate and adaptive immune responses in neurodegeneration and repair. Immunology. 2014;141:287-91.
10. Stower $\mathrm{H}$. Searching for Alzheimer's disease therapies. Nature Medicine. 2018;24:894-7.

11. Deczkowska A, Schwartz M. Targeting neuro-immune communication in neurodegeneration: Challenges and opportunities. J Exp Med. 2018;215: 2702-4.

12. Hu X, Leak RK, Thomson AW, Yu F, Xia Y, Wechsler LR, Chen J. Promises and limitations of immune cell-based therapies in neurological disorders. Nat Rev Neurol. 2018;14:559-68.

13. Brochard V, Combadiere B, Prigent A, Laouar $Y$, Perrin A, Beray-Berthat $V$, Bonduelle $\mathrm{O}$, Alvarez-Fischer D, Callebert J, Launay JM, et al. Infiltration of CD4+ lymphocytes into the brain contributes to neurodegeneration in a mouse model of Parkinson disease. J Clin Invest. 2009;119:182-92.

14. Louveau A, Harris TH, Kipnis J. Revisiting the Mechanisms of CNS Immune Privilege. Trends Immunol. 2015;36:569-77.

15. Bailey SL, Carpentier PA, MCMahon EJ, Begolka WS, Miller SD. Innate and adaptive immune responses of the central nervous system. Crit Rev Immunol. 2006:26:149-88.

16. Benner EJ, Banerjee R, Reynolds AD, Sherman S, Pisarev VM, Tsiperson V, Nemachek C, Ciborowski P, Przedborski S, Mosley RL, Gendelman HE. Nitrated alpha-synuclein immunity accelerates degeneration of nigral dopaminergic neurons. PLoS One. 2008;3:e1376.

17. Kiyota T, Machhi J, Lu Y, Dyavarshetty B, Nemati M, Yokoyama I, Mosley RL, Gendelman HE. Granulocyte-macrophage colony-stimulating factor neuroprotective activities in Alzheimer's disease mice. J Neuroimmunol. 2018;319:80-92.

18. Dombrowski Y, O'Hagan T, Dittmer M, Penalva R, Mayoral SR, Bankhead P, Fleville S, Eleftheriadis G, Zhao C, Naughton M, et al. Regulatory T cells promote myelin regeneration in the central nervous system. Nat Neurosci. 2017:20:674-80.

19. Ransohoff RM, Brown MA. Innate immunity in the central nervous system. J Clin Invest. 2012;122:1164-71.

20. Appel SH, Smith RG, Engelhardt JI, Stefani E. Evidence for autoimmunity in amyotrophic lateral sclerosis. J Neuro/ Sci. 1993;118:169-74.

21. Zhao W, Beers DR, Liao B, Henkel JS, Appel SH. Regulatory T lymphocytes from ALS mice suppress microglia and effector T lymphocytes through different cytokine-mediated mechanisms. Neurobiol Dis. 2012;48:418-28.

22. Reynolds AD, Banerjee R, Liu J, Gendelman HE, Mosley RL. Neuroprotective activities of CD4+CD25+ regulatory $T$ cells in an animal model of Parkinson's disease. J Leukoc Biol. 2007;82:1083-94.

23. Baek H, Ye M, Kang GH, Lee C, Lee G, Choi DB, Jung J, Kim H, Lee S, Kim JS, et al. Neuroprotective effects of CD4+CD25+Foxp3+ regulatory T cells in a 3xTg-AD Alzheimer's disease model. Oncotarget. 2016;7:69347-57.

24. Gendelman HE, Zhang Y, Santamaria P, Olson KE, Schutt CR, Bhatti D, Shetty BLD, Lu Y, Estes KA, Standaert DG, et al. Evaluation of the safety and immunomodulatory effects of sargramostim in a randomized, double-blind phase 1 clinical Parkinson's disease trial. NPJ Parkinsons Dis. 2017;3:10.

25. Olson KE, Kosloski-Bilek LM, Anderson KM, Diggs BJ, Clark BE, Gledhill JM Jr, Shandler SJ, Mosley RL, Gendelman HE. Selective VIP Receptor Agonists Facilitate Immune Transformation for Dopaminergic Neuroprotection in MPTP-Intoxicated Mice. J Neurosci. 2015;35:16463-78.

26. Kosloski LM, Kosmacek EA, Olson KE, Mosley RL, Gendelman HE. GM-CSF induces neuroprotective and anti-inflammatory responses in 1-methyl-4phenyl-1,2,3,6-tetrahydropyridine intoxicated mice. J Neuroimmunol. 2013; 265:1-10.

27. Liesz A, Zhou W, Na SY, Hammerling GJ, Garbi N, Karcher S, Mracsko E, Backs J, Rivest S, Veltkamp R. Boosting regulatory T cells limits neuroinflammation in permanent cortical stroke. J Neurosci. 2013;33:17350-62.

28. Laurie C, Reynolds A, Coskun O, Bowman E, Gendelman HE, Mosley RL. CD4+ T cells from Copolymer-1 immunized mice protect dopaminergic neurons in the 1-methyl-4-phenyl-1,2,3,6-tetrahydropyridine model of Parkinson's disease. J Neuroimmunol. 2007;183:60-8.

29. Benner EJ, Mosley RL, Destache CJ, Lewis TB, Jackson-Lewis V, Gorantla S, Nemachek C, Green SR, Przedborski S, Gendelman HE. Therapeutic immunization protects dopaminergic neurons in a mouse model of Parkinson's disease. Proc Natl Acad Sci U S A. 2004;101:9435-40.

30. Cui G, Zhang Y, Gong Z, Zhang JZ, Zang YQ. Induction of CD4+CD25+ Foxp3+ regulatory $T$ cell response by glatiramer acetate in type 1 diabetes. Cell Res. 2009;19:574-83.

31. Kivisakk P, Tucky B, Wei T, Campbell JJ, Ransohoff RM. Human cerebrospinal fluid contains CD4+ memory T cells expressing gut- or skin-specific trafficking determinants: relevance for immunotherapy. BMC Immunol. 2006;7:14. 
32. Ransohoff RM, Engelhardt B. The anatomical and cellular basis of immune surveillance in the central nervous system. Nat Rev Immunol. 2012;12:623-35.

33. Korin B, Ben-Shaanan TL, Schiller M, Dubovik T, Azulay-Debby H, Boshnak NT, Koren T, Rolls A. High-dimensional, single-cell characterization of the brain's immune compartment. Nat Neurosci. 2017;20:1300-9.

34. Goverman J. Autoimmune T cell responses in the central nervous system. Nat Rev Immunol. 2009:9:393-407.

35. Kawakami N, Lassmann S, Li Z, Odoardi F, Ritter T, Ziemssen T, Klinkert WE, Ellwart JW, Bradl M, Krivacic K, et al. The activation status of neuroantigenspecific $T$ cells in the target organ determines the clinical outcome of autoimmune encephalomyelitis. J Exp Med. 2004;199:185-97.

36. Bartholomaus I, Kawakami N, Odoardi F, Schlager C, Miljkovic D, Ellwart JW, Klinkert WE, Flugel-Koch C, Issekutz TB, Wekerle H, Flugel A. Effector T cell interactions with meningeal vascular structures in nascent autoimmune CNS lesions. Nature. 2009;462:94-8.

37. van Zwam M, Huizinga R, Heijmans $N$, van Meurs $M$, Wierenga-Wolf AF, Melief MJ. Hintzen RQ, t Hart BA, Amor S, Boven LA, Laman JD: Surgical excision of CNS-draining lymph nodes reduces relapse severity in chronicrelapsing experimental autoimmune encephalomyelitis. J Pathol. 2009;217: 543-51.

38. Filiano AJ, Xu Y, Tustison NJ, Marsh RL, Baker W, Smirnov I, Overall CC, Gadani SP, Turner SD, Weng Z, et al. Unexpected role of interferon-gamma in regulating neuronal connectivity and social behaviour. Nature. 2016;535 425-9.

39. Derecki NC, Cardani AN, Yang CH, Quinnies KM, Crihfield A, Lynch KR, Kipnis $J$. Regulation of learning and memory by meningeal immunity: a key role for IL-4. J Exp Med. 2010;207:1067-80.

40. Cao W, Zheng H. Peripheral immune system in aging and Alzheimer's disease. Mol Neurodegener. 2018;13:51.

41. Widner $H$, Brundin P. Immunological aspects of grafting in the mammalian central nervous system. A review and speculative synthesis. Brain Res. 1988; 472:287-324.

42. Fine A. Transplantation in the central nervous system. Sci Am. 1986;255:52-58B.

43. Rasmussen MK, Mestre H, Nedergaard M. The glymphatic pathway in neurological disorders. Lancet Neurol. 2018;17:1016-24.

44. Iliff JJ, Lee H, Yu M, Feng T, Logan J, Nedergaard M, Benveniste H. Brainwide pathway for waste clearance captured by contrast-enhanced MRI. J Clin Invest. 2013;123:1299-309.

45. Engelhardt B, Carare RO, Bechmann I, Flugel A, Laman JD, Weller RO. Vascular, glial, and lymphatic immune gateways of the central nervous system. Acta Neuropathol. 2016;132:317-38.

46. Louveau A, Plog BA, Antila S, Alitalo K, Nedergaard M, Kipnis J. Understanding the functions and relationships of the glymphatic system and meningeal lymphatics. J Clin Invest. 2017;127:3210-9.

47. Iliff JJ, Wang M, Liao Y, Plogg BA, Peng W, Gundersen GA, Benveniste H, Vates GE, Deane R, Goldman SA, et al. A paravascular pathway facilitates CSF flow through the brain parenchyma and the clearance of interstitial solutes, including amyloid beta. Sci Transl Med. 2012;4:147ra111.

48. Korin B, Dubovik T, Rolls A. Mass cytometry analysis of immune cells in the brain. Nat Protoc. 2018;13:377-91.

49. Raphael I, Nalawade S, Eagar TN, Forsthuber TG. T cell subsets and their signature cytokines in autoimmune and inflammatory diseases. Cytokine. 2015;74:5-17.

50. Mills CD, Kincaid K, Alt JM, Heilman MJ, Hill AM. M-1/M-2 macrophages and the Th1/Th2 paradigm. J Immunol. 2000;164:6166-73.

51. Ransohoff RM, Perry VH. Microglial physiology: unique stimuli, specialized responses. Annu Rev Immunol. 2009;27:119-45.

52. Tang Y, Le W. Differential Roles of M1 and M2 Microglia in Neurodegenerative Diseases. Mol Neurobiol. 2016;53:1181-94.

53. Kiyota T, Machhi J, Lu Y, Dyavarshetty B, Nemati M, Zhang G, Mosley RL, Gelbard HA, Gendelman HE. URMC-099 facilitates amyloid-beta clearance in a murine model of Alzheimer's disease. $J$ Neuroinflammation. 2018;15:137.

54. Appel SH, Beers DR, Henkel JS. T cell-microglial dialogue in Parkinson's disease and amyotrophic lateral sclerosis: are we listening? Trends Immunol. 2010;31:7-17.

55. Colombo E, Farina C. Astrocytes: Key Regulators of Neuroinflammation. Trends Immunol. 2016;37:608-20.

56. Li K, Li J, Zheng J, Qin S. Reactive Astrocytes in Neurodegenerative Diseases. Aging Dis. 2019;10:664-75.
57. Phatnani H, Maniatis T. Astrocytes in neurodegenerative disease. Cold Spring Harb Perspect Biol. 2015;7:a020628.

58. Liddelow SA, Barres BA. Reactive Astrocytes: Production, Function, and Therapeutic Potential. Immunity. 2017:46:957-67.

59. Bottcher C, Schlickeiser S, Sneeboer MAM, Kunkel D, Knop A, Paza E, Fidzinski P, Kraus L, Snijders GJL, Kahn RS, et al. Human microglia regional heterogeneity and phenotypes determined by multiplexed single-cell mass cytometry. Nat Neurosci. 2019;22:78-90.

60. Grabert K, Michoel T, Karavolos MH, Clohisey S, Baillie JK, Stevens MP, Freeman TC, Summers KM, McColl BW. Microglial brain region-dependent diversity and selective regional sensitivities to aging. Nat Neurosci. 2016;19:504-16.

61. Jordao MJC, Sankowski R, Brendecke SM, Sagar LG, Tai YH, Tay TL, Schramm E, Armbruster S, Hagemeyer N, et al. Single-cell profiling identifies myeloid cell subsets with distinct fates during neuroinflammation. Science. 2019; 363(6425):eaat7554

62. Ajami B, Samusik N, Wieghofer P, Ho PP, Crotti A, Bjornson Z, Prinz M, Fantl WJ, Nolan GP, Steinman L. Single-cell mass cytometry reveals distinct populations of brain myeloid cells in mouse neuroinflammation and neurodegeneration models. Nat Neurosci. 2018;21:541-51.

63. Stratoulias V, Venero JL, Tremblay ME, Joseph B. Microglial subtypes: diversity within the microglial community. EMBO J. 2019;38:e101997.

64. Ransohoff RM. A polarizing question: do M1 and M2 microglia exist? Nat Neurosci. 2016;19:987-91.

65. Labzin LI, Heneka MT, Latz E. Innate Immunity and Neurodegeneration. Annu Rev Med. 2018;69:437-49.

66. Pacheco R. Cross-talk between T-cells and gut-microbiota in neurodegenerative disorders. Neural Regen Res. 2019;14:2091-2.

67. Ma Q, Xing C, Long W, Wang HY, Liu Q, Wang RF. Impact of microbiota on central nervous system and neurological diseases: the gut-brain axis. $J$ Neuroinflammation. 2019;16:53.

68. Sampson TR, Debelius JW, Thron T, Janssen S, Shastri GG, Ithan ZE, Challis C, Schretter CE, Rocha S, Gradinaru V, et al. Gut Microbiota Regulate Motor Deficits and Neuroinflammation in a Model of Parkinson's Disease. Cell. 2016:167:1469-80 e1412.

69. Berer K, Gerdes LA, Cekanaviciute E, Jia X, Xiao L, Xia Z, Liu C, Klotz L, Stauffer U, Baranzini SE, et al. Gut microbiota from multiple sclerosis patients enables spontaneous autoimmune encephalomyelitis in mice. Proc Natl Acad Sci U S A. 2017:114:10719-24.

70. Zhuang ZQ, Shen LL, Li WW, Fu X, Zeng F, Gui L, Lu Y, Cai M, Zhu C, Tan YL, et al. Gut Microbiota is Altered in Patients with Alzheimer's Disease. J Alzheimers Dis. 2018:63:1337-46.

71. Bauerl C, Collado MC, Diaz Cuevas A, Vina J, Perez Martinez G. Shifts in gut microbiota composition in an APP/PSS1 transgenic mouse model of Alzheimer's disease during lifespan. Lett Appl Microbiol. 2018;66:464-71.

72. Harach T, Marungruang N, Duthilleul N, Cheatham V, Mc Coy KD, Frisoni G, Neher JJ, Fak F, Jucker M, Lasser T, Bolmont T. Reduction of Abeta amyloid pathology in APPPS1 transgenic mice in the absence of gut microbiota. Sci Rep. 2017;7:41802.

73. Choi JG, Kim N, Ju IG, Eo H, Lim SM, Jang SE, Kim DH, Oh MS. Oral administration of Proteus mirabilis damages dopaminergic neurons and motor functions in mice. Sci Rep. 2018;8:1275.

74. Zhang YG, Wu S, Yi J, Xia Y, Jin D, Zhou J, Sun J. Target Intestinal Microbiota to Alleviate Disease Progression in Amyotrophic Lateral Sclerosis. Clin Ther 2017;39:322-36

75. Liu J, Wang F, Liu S, Du J, Hu X, Xiong J, Fang R, Chen W, Sun J. Sodium butyrate exerts protective effect against Parkinson's disease in mice via stimulation of glucagon like peptide-1. J Neurol Sci. 2017;381:176-81.

76. Srivastav S, Neupane S, Bhurtel S, Katila N, Maharjan S, Choi H, Hong JT, Choi DY. Probiotics mixture increases butyrate, and subsequently rescues the nigral dopaminergic neurons from MPTP and rotenone-induced neurotoxicity. J Nutr Biochem. 2019;69:73-86.

77. Ivanov II, Atarashi K, Manel N, Brodie EL, Shima T, Karaoz U, Wei D, Goldfarb KC, Santee CA, Lynch SV, et al. Induction of intestinal Th17 cells by segmented filamentous bacteria. Cell. 2009;139:485-98.

78. Round JL, Mazmanian SK. Inducible Foxp3+ regulatory T-cell development by a commensal bacterium of the intestinal microbiota. Proc Natl Acad Sci U S A. 2010;107:12204-9.

79. Arpaia N, Campbell C, Fan X. Dikiy S, van der Veeken J, deRoos P, Liu H, Cross JR, Pfeffer K, Coffer PJ, Rudensky AY: Metabolites produced by commensal bacteria promote peripheral regulatory T-cell generation. Nature. 2013;504:451-5. 
80. Gonzalez H, Contreras F, Pacheco R. Regulation of the Neurodegenerative Process Associated to Parkinson's Disease by CD4+ T-cells. J Neuroimmune Pharmacol. 2015;10:561-75.

81. Campos-Acuna J, Elgueta D, Pacheco R. T-Cell-Driven Inflammation as a Mediator of the Gut-Brain Axis Involved in Parkinson's Disease. Front Immunol. 2019;10:239.

82. Fung TC, Olson CA, Hsiao EY. Interactions between the microbiota, immune and nervous systems in health and disease. Nat Neurosci. 2017;20:145-55.

83. Erny D. Hrabe de Angelis AL, Jaitin D, Wieghofer P, Staszewski O, David E, Keren-Shaul H, Mahlakoiv T, Jakobshagen K, Buch T, et al: Host microbiota constantly control maturation and function of microglia in the CNS. Nat Neurosci. 2015;18:965-77

84. Matcovitch-Natan O, Winter DR, Giladi A, Vargas Aguilar S, Spinrad A, Sarrazin S, Ben-Yehuda H, David E, Zelada Gonzalez F, Perrin P, et al. Microglia development follows a stepwise program to regulate brain homeostasis. Science. 2016;353:aad8670.

85. Wilson NS, El-Sukkari D, Villadangos JA. Dendritic cells constitutively present self antigens in their immature state in vivo and regulate antigen presentation by controlling the rates of MHC class II synthesis and endocytosis. Blood. 2004;103:2187-95.

86. Raker VK, Domogalla MP, Steinbrink K. Tolerogenic Dendritic Cells for Regulatory T Cell Induction in Man. Front Immunol. 2015;6:569.

87. Domogalla MP, Rostan PV, Raker VK, Steinbrink K. Tolerance through Education: How Tolerogenic Dendritic Cells Shape Immunity. Front Immunol. 2017:8:1764.

88. Banchereau J, Steinman RM. Dendritic cells and the control of immunity. Nature. 1998;392:245-52.

89. Zanoni I, Granucci F. Regulation of antigen uptake, migration, and lifespan of dendritic cell by Toll-like receptors. J Mol Med (Berl). 2010;88:873-80.

90. Malissen B, Gregoire C, Malissen M, Roncagalli R. Integrative biology of T cell activation. Nat Immunol. 2014;15:790-7.

91. Drutman SB, Trombetta ES. Dendritic cells continue to capture and present antigens after maturation in vivo. J Immunol. 2010;185:2140-6.

92. Steinbrink K, Graulich E, Kubsch S, Knop J, Enk AH. CD4(+) and CD8(+) anergic $T$ cells induced by interleukin-10-treated human dendritic cells display antigen-specific suppressor activity. Blood. 2002;99:2468-76.

93. Kryczanowsky F, Raker V, Graulich E, Domogalla MP, Steinbrink K. IL-10modulated human dendritic cells for clinical use: identification of a stable and migratory subset with improved tolerogenic activity. J Immunol. 2016; 197:3607-17.

94. Liu J, Cao X. Regulatory dendritic cells in autoimmunity: A comprehensive review. J Autoimmun. 2015:63:1-12

95. Gonzalez-Rey E, Chorny A, Fernandez-Martin A, Ganea D, Delgado M. Vasoactive intestinal peptide generates human tolerogenic dendritic cells that induce CD4 and CD8 regulatory T cells. Blood. 2006;107:3632-8.

96. Schutt CR, Gendelman HE, Mosley RL. Tolerogenic bone marrow-derived dendritic cells induce neuroprotective regulatory $T$ cells in a model of Parkinson's disease. Mol Neurodegener. 2018;13:26.

97. Olivar R, Luque A, Cardenas-Brito S, Naranjo-Gomez M, Blom AM, Borras FE. Rodriguez de Cordoba S, Zipfel PF, Aran JM: The Complement Inhibitor Factor $\mathrm{H}$ Generates an Anti-Inflammatory and Tolerogenic State in Monocyte-Derived Dendritic Cells. J Immunol. 2016;196:4274-90.

98. Ferreira GB, Vanherwegen AS, Eelen G, Gutierrez ACF, Van Lommel L, Marchal K, Verlinden L, Verstuyf A, Nogueira T, Georgiadou M, et al. Vitamin D3 Induces Tolerance in Human Dendritic Cells by Activation of Intracellular Metabolic Pathways. Cell Rep. 2015;10:711-25.

99. Rutella S, Bonanno G, Procoli A, Mariotti A, de Ritis DG, Curti A, Danese S, Pessina G, Pandolfi S, Natoni F, et al. Hepatocyte growth factor favors monocyte differentiation into regulatory interleukin (IL)-10++|L-12low/neg accessory cells with dendritic-cell features. Blood. 2006;108:218-27.

100. Duffy SS, Keating BA, Perera CJ, Moalem-Taylor G. The role of regulatory $T$ cells in nervous system pathologies. J Neurosci Res. 2018;96:951-68.

101. Mount MP, Lira A, Grimes D, Smith PD, Faucher S, Slack R, Anisman H, Hayley S, Park DS. Involvement of interferon-gamma in microglial-mediated loss of dopaminergic neurons. J Neurosci. 2007;27:3328-37.

102. Kebir H, Kreymborg K, Ifergan I, Dodelet-Devillers A, Cayrol R, Bernard M, Giuliani F, Arbour N, Becher B, Prat A. Human TH17 lymphocytes promote blood-brain barrier disruption and central nervous system inflammation. Nat Med. 2007;13:1173-5.

103. Grebing $M$, Nielsen $H H$, Fenger CD, TJ $K$, von Linstow CU, Clausen BH, Soderman M, Lambertsen KL, Thomassen M, Kruse TA, Finsen B. Myelin- specific T cells induce interleukin-1 beta expression in lesion-reactive microglial-like cells in zones of axonal degeneration. Glia. 2016;64:407-24.

104. Depboylu C, Stricker S, Ghobril JP, Oertel WH, Priller J, Hoglinger GU. Brainresident microglia predominate over infiltrating myeloid cells in activation, phagocytosis and interaction with T-lymphocytes in the MPTP mouse model of Parkinson disease. Exp Neurol. 2012;238:183-91.

105. Rogers J, Luber-Narod J, Styren SD, Civin WH. Expression of immune system-associated antigens by cells of the human central nervous system: relationship to the pathology of Alzheimer's disease. Neurobiol Aging. 1988; 9:339-49.

106. Parachikova A, Agadjanyan MG, Cribbs DH, Blurton-Jones M, Perreau V, Rogers J, Beach TG, Cotman CW. Inflammatory changes parallel the early stages of Alzheimer disease. Neurobiol Aging. 2007;28:1821-33.

107. Dong Y, Benveniste EN. Immune function of astrocytes. Glia. 2001;36:180-90

108. Xie L, Yang SH. Interaction of astrocytes and T cells in physiological and pathological conditions. Brain Res. 1623;2015:63-73.

109. Tan L, Gordon KB, Mueller JP, Matis LA, Miller SD. Presentation of proteolipid protein epitopes and B7-1-dependent activation of encephalitogenic T cells by IFN-gamma-activated SJL/J astrocytes. J Immunol. 1998;160:4271-9.

110. Soos JM, Ashley TA, Morrow J, Patarroyo JC, Szente BE, Zamvil SS. Differential expression of B7 co-stimulatory molecules by astrocytes correlates with T cell activation and cytokine production. Int Immunol. 1999; 11:1169-79.

111. Bechmann I, Steiner B, Gimsa U, Mor G, Wolf S, Beyer M, Nitsch R, Zipp F. Astrocyte-induced T cell elimination is CD95 ligand dependent. J Neuroimmunol. 2002;132:60-5.

112. Lee $M, M c G e e r E, M c G e e r ~ P L$. Neurotoxins released from interferon-gammastimulated human astrocytes. Neuroscience. 2013;229:164-75.

113. Zhou Y, Sonobe $Y$, Akahori T, Jin S, Kawanokuchi J, Noda M, Iwakura Y, Mizuno T, Suzumura A. IL-9 promotes Th17 cell migration into the central nervous system via CC chemokine ligand-20 produced by astrocytes. J Immunol. 2011;186:4415-21.

114. Giuliani F, Goodyer CG, Antel JP, Yong WW. Vulnerability of human neurons to T cell-mediated cytotoxicity. J Immunol. 2003;171:368-79.

115. Liu Z, Huang Y, Cao BB, Qiu YH, Peng YP. Th17 Cells Induce Dopaminergic Neuronal Death via LFA-1/ICAM-1 Interaction in a Mouse Model of Parkinson's Disease. Mol Neurobiol. 2017;54:7762-76.

116. Lowther DE, Hafler DA. Regulatory T cells in the central nervous system. Immunol Rev. 2012;248:156-69.

117. Xie L, Choudhury GR, Winters A, Yang SH, Jin K. Cerebral regulatory T cells restrain microglia/macrophage-mediated inflammatory responses via IL-10. Eur J Immunol. 2015;45:180-91.

118. Saunders JA, Estes KA, Kosloski LM, Allen HE, Dempsey KM, Torres-Russotto DR, Meza JL, Santamaria PM, Bertoni JM, Murman DL, et al. CD4+ regulatory and effector/memory T cell subsets profile motor dysfunction in Parkinson's disease. J Neuroimmune Pharmacol. 2012;7:927-38,

119. Ito M, Komai K, Mise-Omata S, lizuka-Koga M, Noguchi $Y$, Kondo T, Sakai R, Matsuo K, Nakayama T, Yoshie O, et al. Brain regulatory T cells suppress astrogliosis and potentiate neurological recovery. Nature. 2019;565:246-50.

120. Huang Y, Liu Z, Cao BB, Qiu YH, Peng YP. Treg Cells Protect Dopaminergic Neurons against MPP+ Neurotoxicity via CD47-SIRPA Interaction. Cell Physio Biochem. 2017:41:1240-54.

121. Weber RD. Michigan's Malpractice Reform Legislation: what you need to know. J Mich Dent Assoc. 1993;75:38-9 34

122. Li P, Wang L, Zhou Y, Gan Y, Zhu W, Xia Y, Jiang X, Watkins S, Vazquez A, Thomson AW, et al. C-C Chemokine Receptor Type 5 (CCR5)-Mediated Docking of Transferred Tregs Protects Against Early Blood-Brain Barrier Disruption After Stroke. J Am Heart Assoc. 2017;6.

123. Deliyanti D, Talia DM, Zhu T, Maxwell MJ, Agrotis A, Jerome JR, Hargreaves EM, Gerondakis S, Hibbs ML, Mackay F, Wilkinson-Berka JL. Foxp3(+) Tregs are recruited to the retina to repair pathological angiogenesis. Nat Commun. 2017:8:748.

124. Gandolfo MT, Jang HR, Bagnasco SM, Ko GJ, Agreda P, Satpute SR, Crow MT, King LS, Rabb H. Foxp3+ regulatory T cells participate in repair of ischemic acute kidney injury. Kidney Int. 2009;76:717-29.

125. Haertel E, Joshi N, Hiebert P, Kopf M, Werner S. Regulatory T cells are required for normal and activin-promoted wound repair in mice. Eur $J$ Immunol. 2018:48:1001-13.

126. Togo T, Akiyama H, Iseki E, Kondo H, Ikeda K, Kato M, Oda T, Tsuchiya K, Kosaka K. Occurrence of T cells in the brain of Alzheimer's disease and other neurological diseases. J Neuroimmunol. 2002;124:83-92. 
127. Bielekova B, Goodwin B, Richert N, Cortese I, Kondo T, Afshar G, Gran B, Eaton J, Antel J, Frank JA, et al. Encephalitogenic potential of the myelin basic protein peptide (amino acids 83-99) in multiple sclerosis: results of a phase II clinical trial with an altered peptide ligand. Nat Med. 2000;6:1167-75.

128. Ciccarelli O, Barkhof F, Bodini B, De Stefano N, Golay X, Nicolay K, Pelletier D, Pouwels PJ, Smith SA, Wheeler-Kingshott CA, et al. Pathogenesis of multiple sclerosis: insights from molecular and metabolic imaging. Lancet Neurol. 2014;13:807-22

129. Chou YK, Bourdette DN, Offner H, Whitham R, Wang RY, Hashim GA, Vandenbark AA. Frequency of $T$ cells specific for myelin basic protein and myelin proteolipid protein in blood and cerebrospinal fluid in multiple sclerosis. J Neuroimmunol. 1992;38:105-13.

130. Zhang J, Markovic-Plese S, Lacet B, Raus J, Weiner HL, Hafler DA. Increased frequency of interleukin 2-responsive $T$ cells specific for myelin basic protein and proteolipid protein in peripheral blood and cerebrospinal fluid of patients with multiple sclerosis. J Exp Med. 1994;179:973-84.

131. Kebir H, Ifergan I, Alvarez JI, Bernard M, Poirier J, Arbour N, Duquette P, Prat A. Preferential recruitment of interferon-gamma-expressing TH17 cells in multiple sclerosis. Ann Neurol. 2009;66:390-402.

132. Stromnes IM, Goverman JM. Active induction of experimental allergic encephalomyelitis. Nat Protoc. 2006;1:1810-9.

133. Stromnes IM, Goverman JM. Passive induction of experimental allergic encephalomyelitis. Nat Protoc. 2006;1:1952-60.

134. Glabinski AR, Tani M, Tuohy VK, Ransohoff RM. Murine experimental autoimmune encephalomyelitis: a model of immune-mediated inflammation and multiple sclerosis. Methods Enzymol. 1997;288:182-90.

135. Jager A, Dardalhon V, Sobel RA, Bettelli E, Kuchroo VK. Th1, Th17, and Th9 effector cells induce experimental autoimmune encephalomyelitis with different pathological phenotypes. J Immunol. 2009;183:7169-77.

136. Domingues HS, Mues M, Lassmann H, Wekerle H, Krishnamoorthy G. Functional and pathogenic differences of Th1 and Th17 cells in experimental autoimmune encephalomyelitis. PLoS One. 2010;5:e15531.

137. Axtell RC, de Jong BA, Boniface K, van der Voort LF, Bhat R, De Sarno P, Naves R, Han M, Zhong F, Castellanos JG, et al. T helper type 1 and 17 cells determine efficacy of interferon-beta in multiple sclerosis and experimental encephalomyelitis. Nat Med. 2010;16:406-12.

138. Pierson E, Simmons SB, Castelli L, Goverman JM. Mechanisms regulating regional localization of inflammation during CNS autoimmunity. Immunol Rev. 2012;248:205-15.

139. Danikowski KM, Jayaraman S, Prabhakar BS. Regulatory T cells in multiple sclerosis and myasthenia gravis. J Neuroinflammation. 2017;14:117.

140. Viglietta V, Baecher-Allan C, Weiner HL, Hafler DA. Loss of functional suppression by CD4+CD25+ regulatory $T$ cells in patients with multiple sclerosis. J Exp Med. 2004;199:971-9.

141. Li YF, Zhang SX, Ma XW, Xue YL, Gao C, Li XY, Xu AD. The proportion of peripheral regulatory $T$ cells in patients with Multiple Sclerosis: A metaanalysis. Mult Scler Relat Disord. 2019;28:75-80

142. Sloane E, Ledeboer A, Seibert W, Coats B, van Strien M, Maier SF, Johnson KW, Chavez R, Watkins LR, Leinwand L, et al. Anti-inflammatory cytokine gene therapy decreases sensory and motor dysfunction in experimental Multiple Sclerosis: MOG-EAE behavioral and anatomical symptom treatment with cytokine gene therapy. Brain Behav Immun. 2009:23:92-100.

143. Ephrem A, Chamat S, Miquel C, Fisson S, Mouthon L, Caligiuri G, Delignat S, Elluru S, Bayry J, Lacroix-Desmazes S, et al. Expansion of CD4+CD25+ regulatory $T$ cells by intravenous immunoglobulin: a critical factor in controlling experimental autoimmune encephalomyelitis. Blood. 2008;111:715-22.

144. Fernandez-Martin A, Gonzalez-Rey E, Chorny A, Ganea D, Delgado M. Vasoactive intestinal peptide induces regulatory $T$ cells during experimental autoimmune encephalomyelitis. Eur J Immunol. 2006;36:318-26.

145. Serpero LD, Filaci G, Parodi A, Battaglia F, Kalli F, Brogi D, Mancardi GL, Uccelli A, Fenoglio D. Fingolimod modulates peripheral effector and regulatory T cells in MS patients. J Neuroimmune Pharmacol. 2013;8:1106-13.

146. Dominguez-Villar M, Raddassi K, Danielsen AC, Guarnaccia J, Hafler DA Fingolimod modulates $T$ cell phenotype and regulatory $T$ cell plasticity in vivo. J Autoimmun. 2019:96:40-9.

147. Prince $M$, Bryce $R$, Albanese $E$, Wimo A, Ribeiro W, Ferri CP. The global prevalence of dementia: a systematic review and metaanalysis. Alzheimers Dement. 2013;9:63-75 e62.

148. Castellani RJ, Rolston RK, Smith MA. Alzheimer disease. Dis Mon. 2010;56: 484-546.
149. Schenk D, Barbour R, Dunn W, Gordon G, Grajeda H, Guido T, Hu K, Huang J, Johnson-Wood K, Khan K, et al. Immunization with amyloid-beta attenuates Alzheimer-disease-like pathology in the PDAPP mouse. Nature. 1999:400:173-7.

150. Nicoll JA, Wilkinson D, Holmes C, Steart P, Markham H, Weller RO. Neuropathology of human Alzheimer disease after immunization with amyloid-beta peptide: a case report. Nat Med. 2003;9:448-52.

151. Monsonego A, Imitola J, Petrovic S, Zota V, Nemirovsky A, Baron R, Fisher Y, Owens T, Weiner HL. Abeta-induced meningoencephalitis is IFN-gammadependent and is associated with T cell-dependent clearance of Abeta in a mouse model of Alzheimer's disease. Proc Natl Acad Sci U S A. 2006;103: 5048-53.

152. Cao C, Arendash GW, Dickson A, Mamcarz MB, Lin X, Ethell DW. Abetaspecific Th2 cells provide cognitive and pathological benefits to Alzheimer's mice without infiltrating the CNS. Neurobiol Dis. 2009;34:63-70.

153. Rossi B, Angiari S, Zenaro E, Budui SL, Constantin G. Vascular inflammation in central nervous system diseases: adhesion receptors controlling leukocyte-endothelial interactions. J Leukoc Biol. 2011;89:539-56.

154. Ferretti MT, Merlini M, Spani C, Gericke C, Schweizer N, Enzmann G, Engelhardt B, Kulic L, Suter T, Nitsch RM. T-cell brain infiltration and immature antigen-presenting cells in transgenic models of Alzheimer's disease-like cerebral amyloidosis. Brain Behav Immun. 2016;54:211-25.

155. McManus RM, Higgins SC, Mills KH, Lynch MA. Respiratory infection promotes T cell infiltration and amyloid-beta deposition in APP/PS1 mice. Neurobiol Aging. 2014;35:109-21.

156. Bu XL, Yao XQ, Jiao SS, Zeng F, Liu YH, Xiang Y, Liang CR, Wang QH, Wang $X$, Cao HY, et al. A study on the association between infectious burden and Alzheimer's disease. Eur J Neurol. 2015;22:1519-25.

157. Lim SL, Rodriguez-Ortiz CJ, Kitazawa M. Infection, systemic inflammation, and Alzheimer's disease. Microbes Infect. 2015:17:549-56.

158. Strandberg TE, Pitkala KH, Linnavuori KH, Tilvis RS. Impact of viral and bacterial burden on cognitive impairment in elderly persons with cardiovascular diseases. Stroke. 2003;34:2126-31.

159. Li J, Wang YJ, Zhang M, Xu ZQ, Gao CY, Fang CQ, Yan JC, Zhou HD. Chongqing Ageing Study G: Vascular risk factors promote conversion from mild cognitive impairment to Alzheimer disease. Neurology. 2011; 76:1485-91

160. Browne TC, McQuillan K, McManus RM, O'Reilly JA, Mills KH, Lynch MA. IFNgamma Production by amyloid beta-specific Th1 cells promotes microglial activation and increases plaque burden in a mouse model of Alzheimer's disease. J Immunol. 2013;190:2241-51.

161. Gate D, Saligrama N, Leventhal O, Yang AC, Unger MS, Middeldorp J, Chen K, Lehallier B, Channappa D, De Los Santos MB, et al. Clonally expanded CD8 T cells patrol the cerebrospinal fluid in Alzheimer's disease. Nature. 2020:577:399-404.

162. Lueg G, Gross CC, Lohmann H, Johnen A, Kemmling A, Deppe M, Groger J, Minnerup J, Wiendl H, Meuth SG, Duning T. Clinical relevance of specific Tcell activation in the blood and cerebrospinal fluid of patients with mild Alzheimer's disease. Neurobiol Aging. 2015;36:81-9.

163. Merlini M, Kirabali T, Kulic L, Nitsch RM, Ferretti MT. Extravascular CD3+ T Cells in Brains of Alzheimer Disease Patients Correlate with Tau but Not with Amyloid Pathology: An Immunohistochemical Study. Neurodegener Dis. 2018;18:49-56.

164. Saresella M, Calabrese E, Marventano I, Piancone F, Gatti A, Alberoni M, Nemni R, Clerici M. Increased activity of Th-17 and Th-9 lymphocytes and a skewing of the post-thymic differentiation pathway are seen in Alzheimer's disease. Brain Behav Immun. 2011;25:539-47.

165. Agnes $P$, Christiane $S$, Peter D. T-cells show increased production of cytokines and activation markers in Alzheimer's disease. Brain Disord Ther. 2013:3:3-112.

166. Heneka MT, O'Banion MK, Terwel D, Kummer MP. Neuroinflammatory processes in Alzheimer's disease. J Neural Transm (Vienna). 2010;117:919-47.

167. Chui R, Dorovini-Zis K. Regulation of CCL2 and CCL3 expression in human brain endothelial cells by cytokines and lipopolysaccharide. J Neuroinflammation. 2010;7:1.

168. Oberstein TJ, Taha L, Spitzer P, Hellstern J, Herrmann M, Kornhuber J, Maler JM. Imbalance of Circulating Th17 and Regulatory T Cells in Alzheimer's Disease: A Case Control Study. Front Immunol. 2018:9:1213.

169. Zhang J, Ke KF, Liu Z, Qiu YH, Peng YP. Th17 cell-mediated neuroinflammation is involved in neurodegeneration of abeta1-42-induced Alzheimer's disease model rats. PLoS One. 2013;8:e75786. 
170. Larbi A, Pawelec G, Witkowski JM, Schipper HM, Derhovanessian E, Goldeck D, Fulop T. Dramatic shifts in circulating CD4 but not CD8 T cell subsets in mild Alzheimer's disease. J Alzheimers Dis. 2009;17:91-103.

171. Avidan H, Kipnis J, Butovsky O, Caspi RR, Schwartz M. Vaccination with autoantigen protects against aggregated beta-amyloid and glutamate toxicity by controlling microglia: effect of CD4+CD25+ T cells. Eur J Immunol. 2004;34:3434-45.

172. Rosenkranz D, Weyer S, Tolosa E, Gaenslen A, Berg D, Leyhe T, Gasser T, Stoltze $L$. Higher frequency of regulatory $T$ cells in the elderly and increased suppressive activity in neurodegeneration. J Neuroimmunol. 2007;188:117-27.

173. Baruch K, Rosenzweig N, Kertser A, Deczkowska A, Sharif AM, Spinrad A Tsitsou-Kampeli A, Sarel A, Cahalon L, Schwartz M. Breaking immune tolerance by targeting Foxp3(+) regulatory T cells mitigates Alzheimer's disease pathology. Nat Commun. 2015;6:7967.

174. Ciccocioppo F, Lanuti P, Pierdomenico L, Simeone P, Bologna G, Ercolino E, Buttari F, Fantozzi R, Thomas A, Onofrj M, et al. The Characterization of Regulatory T-Cell Profiles in Alzheimer's Disease and Multiple Sclerosis. Sci Rep. 2019;9:8788.

175. Dansokho C, Ait Ahmed D, Aid S, Toly-Ndour C, Chaigneau T, Calle V, Cagnard N, Holzenberger M, Piaggio E, Aucouturier P, Dorothee G. Regulatory $T$ cells delay disease progression in Alzheimer-like pathology. Brain. 2016;139:1237-51.

176. Yang $H$, Yang $H$, Xie $Z$, Wei $L$, Bi J. Systemic transplantation of human umbilical cord derived mesenchymal stem cells-educated T regulatory cells improved the impaired cognition in AbetaPPswe/PS1dE9 transgenic mice. PLoS One. 2013;8:e69129.

177. Alves S, Churlaud G, Audrain M, Michaelsen-Preusse K, Fol R, Souchet B, Braudeau J, Korte M, Klatzmann D, Cartier N. Interleukin-2 improves amyloid pathology, synaptic failure and memory in Alzheimer's disease mice. Brain. 2017:140:826-42.

178. Ye M, Chung HS, Lee C, Yoon MS, Yu AR, Kim JS, Hwang DS, Shim I, Bae H. Neuroprotective effects of bee venom phospholipase A2 in the $3 x \operatorname{Tg~AD~}$ mouse model of Alzheimer's disease. J Neuroinflammation. 2016;13:10.

179. Aytan N, Choi JK, Carreras I, Brinkmann V, Kowall NW, Jenkins BG, Dedeoglu A. Fingolimod modulates multiple neuroinflammatory markers in a mouse model of Alzheimer's disease. Sci Rep. 2016;6:24939.

180. Gao C, Qian Y, Huang J, Wang D, Su W, Wang P, Guo L, Quan W, An S, Zhang J, Jiang R. A Three-Day Consecutive Fingolimod Administration Improves Neurological Functions and Modulates Multiple Immune Responses of CCI Mice. Mol Neurobiol. 2017;54:8348-60.

181. Potter H, Woodcock JH, Boyd T, Sillau SH, Bettcher BM, Daniels J, Heffernan KS, Gray H. Interim report of a phase 2 pilot safety and efficacy trial of gmcsf/leukine $\langle\text { sup }\rangle^{\oplus}</$ sup $>$ in mild-to-moderate alzheimer's diseasE. Alzheimer's \& Dementia: J Alzheimer's Assoc. 2017;13:P1572.

182. Kurkowska-Jastrzebska I, Wronska A, Kohutnicka M, Czlonkowski A, Czlonkowska A. The inflammatory reaction following 1-methyl-4-phenyl-1,2,3, 6-tetrahydropyridine intoxication in mouse. Exp Neurol. 1999;156:50-61.

183. Chen Y, Qi B, Xu W, Ma B, Li L, Chen Q, Qian W, Liu X, Qu H. Clinical correlation of peripheral CD4+cell subsets, their imbalance and Parkinson's disease. Mol Med Rep. 2015;12:6105-11.

184. Kustrimovic N, Comi C, Magistrelli L, Rasini E, Legnaro M, Bombelli R, Aleksic I, Blandini F, Minafra B, Riboldazzi G, et al. Parkinson's disease patients have a complex phenotypic and functional Th1 bias: cross-sectional studies of CD4+ Th1/Th2/T17 and Treg in drug-naive and drug-treated patients. J Neuroinflammation. 2018;15:205.

185. Baba Y, Kuroiwa A, Uitti RJ, Wszolek ZK, Yamada T. Alterations of Tlymphocyte populations in Parkinson disease. Parkinsonism Relat Disord. 2005;11:493-8.

186. Bas J, Calopa M, Mestre M, Mollevi DG, Cutillas B, Ambrosio S, Buendia E. Lymphocyte populations in Parkinson's disease and in rat models of parkinsonism. J Neuroimmunol. 2001;113:146-52.

187. Chen S, Liu Y, Niu Y, Xu Y, Zhou Q, Xu X, Wang J, Yu M. Increased abundance of myeloid-derived suppressor cells and Th17 cells in peripheral blood of newly-diagnosed Parkinson's disease patients. Neurosci Lett. 2017; 648:21-5.

188. Takahashi T, Sakaguchi S. Naturally arising CD25+CD4+ regulatory T cells in maintaining immunologic self-tolerance and preventing autoimmune disease. Curr Mol Med. 2003;3:693-706.

189. Chung ES, Kim H, Lee G, Park S, Kim H, Bae H. Neuro-protective effects of bee venom by suppression of neuroinflammatory responses in a mouse model of Parkinson's disease: role of regulatory T cells. Brain Behav Immun 2012;26:1322-30.

190. Arnon R, Aharoni R. Mechanism of action of glatiramer acetate in multiple sclerosis and its potential for the development of new applications. Proc Natl Acad Sci U S A. 2004;101(Suppl 2):14593-8.

191. Putheti P, Soderstrom M, Link H, Huang YM. Effect of glatiramer acetate (Copaxone) on CD4+CD25high T regulatory cells and their IL-10 production in multiple sclerosis. J Neuroimmunol. 2003;144:125-31.

192. Kim NK, Choi BH, Huang X, Snyder BJ, Bukhari S, Kong TH, Park H, Park HC, Park SR, Ha Y. Granulocyte-macrophage colony-stimulating factor promotes survival of dopaminergic neurons in the 1-methyl-4-phenyl-1,2,3,6tetrahydropyridine-induced murine Parkinson's disease model. Eur J Neurosci. 2009:29:891-900

193. Zhou TT, Zu G, Wang X, Zhang XG, Li S, Liang ZH, Zhao J. Immunomodulatory and neuroprotective effects of ginsenoside Rg1 in the MPTP(1-methyl-4-phenyl-1,2,3,6-tetrahydropyridine) -induced mouse model of Parkinson's disease. Int Immunopharmacol. 2015;29:334-43.

194. Yang Y, Li X, Zhang L, Liu L, Jing G, Cai H. Ginsenoside Rg1 suppressed inflammation and neuron apoptosis by activating PPARgamma/HO-1 in hippocampus in rat model of cerebral ischemia-reperfusion injury. Int J Clin Exp Pathol. 2015:8:2484-94

195. Chung ES, Lee G, Lee C, Ye M, Chung HS, Kim H, Bae SJ, Hwang DS, Bae H. Bee Venom Phospholipase A2, a Novel Foxp3+ Regulatory T Cell Inducer, Protects Dopaminergic Neurons by Modulating Neuroinflammatory Responses in a Mouse Model of Parkinson's Disease. J Immunol. 2015;195: 4853-60.

196. Chen MF, Gill AJ, Kolson DL. Neuropathogenesis of HIV-associated neurocognitive disorders: roles for immune activation, HIV blipping and viral tropism. Curr Opin HIV AIDS. 2014;9:559-64.

197. Antinori A, Ammassari A, De Luca A, Cingolani A, Murri R, Scoppettuolo G, Fortini M, Tartaglione T, Larocca LM, Zannoni G, et al. Diagnosis of AIDSrelated focal brain lesions: a decision-making analysis based on clinical and neuroradiologic characteristics combined with polymerase chain reaction assays in CSF. Neurology. 1997:48:687-94.

198. Beers DR, Henkel JS, Zhao W, Wang J, Huang A, Wen S, Liao B, Appel SH. Endogenous regulatory $T$ lymphocytes ameliorate amyotrophic lateral sclerosis in mice and correlate with disease progression in patients with amyotrophic lateral sclerosis. Brain. 2011;134:1293-314.

199. Vassallo M, Durant J, Lebrun-Frenay C, Fabre R, Ticchioni M, Andersen S, DeSalvador F, Harvey-Langton A, Dunais B, Cohen-Codar I, et al. Virologically suppressed patients with asymptomatic and symptomatic HIV-associated neurocognitive disorders do not display the same pattern of immune activation. HIV Med. 2015;16:431-40.

200. Serrano-Villar S, Moreno S, Fuentes-Ferrer M, Sanchez-Marcos C, Avila M, Sainz T, de Villar NG, Fernandez-Cruz A, Estrada V. The CD4:CD8 ratio is associated with markers of age-associated disease in virally suppressed HIV-infected patients with immunological recovery. HIV Med. 2014;15: 40-9.

201. Li P, Mao L, Zhou G, Leak RK, Sun BL, Chen J, Hu X. Adoptive regulatory Tcell therapy preserves systemic immune homeostasis after cerebral ischemia. Stroke. 2013;44:3509-15.

202. Li P, Gan Y, Sun BL, Zhang F, Lu B, Gao Y, Liang W, Thomson AW, Chen J, Hu $X$. Adoptive regulatory T-cell therapy protects against cerebral ischemia. Ann Neurol. 2013;74:458-71.

203. Grauer OM, Reichelt D, Gruneberg U, Lohmann H, Schneider-Hohendorf T, Schulte-Mecklenbeck A, Gross CC, Meuth SG, Wiendl H, Husstedt IW. Neurocognitive decline in HIV patients is associated with ongoing T-cell activation in the cerebrospinal fluid. Ann Clin Transl Neurol. 2015;2:906-19.

204. Marziali M, De Santis W, Carello R, Leti W, Esposito A, Isgro A, Fimiani C, Sirianni MC, Mezzaroma I, Aiuti F. T-cell homeostasis alteration in HIV-1 infected subjects with low CD4 T-cell count despite undetectable virus load during HAART. AIDS. 2006;20:2033-41.

205. Mendez-Lagares G, Pozo-Balado MM, Genebat M, Garcia Perganeda A, Leal M, Pacheco YM. Severe immune dysregulation affects CD4(+ CD25(hi)FoxP3(+) regulatory T cells in HIV-infected patients with low-level CD4 T-cell repopulation despite suppressive highly active antiretroviral therapy. J Infect Dis. 2012;205:1501-9.

206. Valiathan R, Asthana D. Increase in frequencies of circulating Th-17 cells correlates with microbial translocation, immune activation and exhaustion in HIV-1 infected patients with poor CD4 T-cell reconstitution. Immunobiology. 2016;221:670-8. 
207. Sheean RK, McKay FC, Cretney E, Bye CR, Perera ND, Tomas D, Weston RA, Scheller KJ, Djouma E, Menon P, et al. Association of Regulatory T-Cell Expansion With Progression of Amyotrophic Lateral Sclerosis: A Study of Humans and a Transgenic Mouse Model. JAMA Neurol. 2018;75:681-9.

208. Zhang H, Xia Y, Ye Q, Yu F, Zhu W, Li P, Wei Z, Yang Y, Shi Y, Thomson AW, et al. In Vivo Expansion of Regulatory T Cells with IL-2/L-2 Antibody Complex Protects against Transient Ischemic Stroke. J Neurosci. 2018;38: 10168-79.

209. Gaardbo JC, Nielsen SD, Vedel SJ, Ersboll AK, Harritshoj L, Ryder LP, Nielsen JO, Kolte L. Regulatory T cells in human immunodeficiency virus-infected patients are elevated and independent of immunological and virological status, as well as initiation of highly active anti-retroviral therapy. Clin Exp Immunol. 2008;154:80-6.

210. Kleinman AJ, Sivanandham R, Pandrea I, Chougnet CA, Apetrei C. Regulatory T Cells As Potential Targets for HIV Cure Research. Front Immunol. 2018;9:734.

211. Ambada GN, Ntsama CE, Nji NN, Ngu LN, Sake CN, Lissom A, Tchouangeu FT, Tchadji J, Sosso M, Etoa FX, Nchinda GW. Phenotypic characterization of regulatory T cells from antiretroviral-naive HIV-1-infected people. Immunology. 2017;151:405-16.

212. Chevalier MF, Weiss L. The split personality of regulatory T cells in HIV infection. Blood. 2013;121:29-37.

213. Kiernan MC, Vucic S, Cheah BC, Turner MR, Eisen A, Hardiman O, Burrell JR, Zoing MC. Amyotrophic lateral sclerosis. Lancet. 2011;377:942-55.

214. Beers DR, Appel SH. Immune dysregulation in amyotrophic lateral sclerosis: mechanisms and emerging therapies. Lancet Neurol. 2019;18:211-20.

215. Beers DR, Zhao W, Appel SH. The Role of Regulatory T Lymphocytes in Amyotrophic Lateral Sclerosis. JAMA Neurol. 2018;75:656-8.

216. Troost D, van den Oord JJ, de Jong JM, Swaab DF. Lymphocytic infiltration in the spinal cord of patients with amyotrophic lateral sclerosis. Clin Neuropathol. 1989;8:289-94.

217. Kawamata T, Akiyama H, Yamada T, McGeer PL. Immunologic reactions in amyotrophic lateral sclerosis brain and spinal cord tissue. Am J Pathol. 1992; 140:691-707.

218. Engelhardt JI, Tajti J, Appel SH. Lymphocytic infiltrates in the spinal cord in amyotrophic lateral sclerosis. Arch Neurol. 1993;50:30-6.

219. Graves MC, Fiala M, Dinglasan LA, Liu NQ, Sayre J, Chiappelli F, van Kooten C, Vinters HV. Inflammation in amyotrophic lateral sclerosis spinal cord and brain is mediated by activated macrophages, mast cells and T cells. Amyotroph Lateral Scler Other Motor Neuron Disord. 2004;5:213-9.

220. Beers DR, Henkel JS, Zhao W, Wang J, Appel SH. CD4+ T cells support glial neuroprotection, slow disease progression, and modify glial morphology in an animal model of inherited ALS. Proc Natl Acad Sci U S A. 2008;105:15558-63.

221. Saresella M, Piancone F, Tortorella P, Marventano I, Gatti A, Caputo D, Lunetta C, Corbo M, Rovaris M, Clerici M. T helper-17 activation dominates the immunologic milieu of both amyotrophic lateral sclerosis and progressive multiple sclerosis. Clin Immunol. 2013;148:79-88.

222. Rentzos M, Evangelopoulos E, Sereti E, Zouvelou V, Marmara S, Alexakis T, Evdokimidis I. Alterations of T cell subsets in ALS: a systemic immune activation? Acta Neurol Scand. 2012:125:260-4.

223. Henkel JS, Beers DR, Wen S, Rivera AL, Toennis KM, Appel JE, Zhao W, Moore DH, Powell SZ, Appel SH. Regulatory T-lymphocytes mediate amyotrophic lateral sclerosis progression and survival. EMBO Mol Med. 2013; 5:64-79.

224. Beers DR, Zhao W, Wang J, Zhang X, Wen S, Neal D, Thonhoff JR, Alsuliman AS, Shpall EJ, Rezvani K, Appel SH. ALS patients' regulatory T lymphocytes are dysfunctional, and correlate with disease progression rate and severity. JCl Insight. 2017;2:e89530.

225. Thonhoff JR, Beers DR, Zhao W, Pleitez M, Simpson EP, Berry JD, Cudkowicz ME, Appel SH. Expanded autologous regulatory T-lymphocyte infusions in ALS: A phase I, first-in-human study. Neurol Neuroimmunol Neuroinflamm. 2018:5:e465.

226. Berry JD, Paganoni S, Atassi N, Macklin EA, Goyal N, Rivner M, Simpson E, Appel S, Grasso DL, Mejia NI, et al. Phase lla trial of fingolimod for amyotrophic lateral sclerosis demonstrates acceptable acute safety and tolerability. Muscle Nerve. 2017;56:1077-84

227. Potenza RL, De Simone R, Armida M, Mazziotti V, Pezzola A, Popoli P, Minghetti L. Fingolimod: A Disease-Modifier Drug in a Mouse Model of Amyotrophic Lateral Sclerosis. Neurotherapeutics. 2016;13:918-27.

228. Liu J, Gong N, Huang X, Reynolds AD, Mosley RL, Gendelman HE. Neuromodulatory activities of $\mathrm{CD} 4+\mathrm{CD} 25$ + regulatory $T$ cells in a murine model of HIV-1-associated neurodegeneration. J Immunol. 2009;182:3855-65.
229. Xia Y, Cai W, Thomson AW, Hu X. Regulatory T Cell Therapy for Ischemic Stroke: how far from Clinical Translation? Trans/ Stroke Res. 2016;7:415-9.

230. Sairanen T, Karjalainen-Lindsberg ML, Paetau A, ljas P, Lindsberg PJ. Apoptosis dominant in the periinfarct area of human ischaemic stroke--a possible target of antiapoptotic treatments. Brain. 2006;129:189-99.

231. Brait VH, Arumugam TV, Drummond GR, Sobey CG. Importance of T lymphocytes in brain injury, immunodeficiency, and recovery after cerebral ischemia. J Cereb Blood Flow Metab. 2012;32:598-611.

232. McColl BW, Rothwell NJ, Allan SM. Systemic inflammatory stimulus potentiates the acute phase and CXC chemokine responses to experimental stroke and exacerbates brain damage via interleukin-1- and neutrophildependent mechanisms. J Neurosci. 2007;27:4403-12.

233. Konoeda F, Shichita T, Yoshida H, Sugiyama Y, Muto G, Hasegawa E, Morita R, Suzuki N, Yoshimura A. Therapeutic effect of IL-12/23 and their signaling pathway blockade on brain ischemia model. Biochem Biophys Res Commun. 2010;402:500-6.

234. Yilmaz G, Arumugam TV, Stokes KY, Granger DN. Role of T lymphocytes and interferon-gamma in ischemic stroke. Circulation. 2006;113:2105-12.

235. Llovera G, Hofmann K, Roth S, Salas-Perdomo A, Ferrer-Ferrer M, Perego C, Zanier ER, Mamrak U, Rex A, Party H, et al. Results of a preclinical randomized controlled multicenter trial (pRCT): Anti-CD49d treatment for acute brain ischemia. Sci Transl Med. 2015;7:-299ra121.

236. Liesz A, Dalpke A, Mracsko E, Antoine DJ, Roth S, Zhou W, Yang H, Na SY, Akhisaroglu M, Fleming T, et al. DAMP signaling is a key pathway inducing immune modulation after brain injury. J Neurosci. 2015;35:583-98.

237. Iadecola C, Anrather J. The immunology of stroke: from mechanisms to translation. Nat Med. 2011;17:796-808.

238. Kamel $\mathrm{H}$, ladecola C. Brain-immune interactions and ischemic stroke: clinical implications. Arch Neurol. 2012;69:576-81.

239. Li GZ, Zhong D, Yang LM, Sun B, Zhong ZH, Yin YH, Cheng J, Yan BB, Li HL. Expression of interleukin-17 in ischemic brain tissue. Scand I Immunol. 2005; 62:481-6.

240. Shichita T, Sugiyama Y, Ooboshi H, Sugimori H, Nakagawa R, Takada I, Iwaki T, Okada Y, lida M, Cua DJ, et al. Pivotal role of cerebral interleukin-17producing gammadeltaT cells in the delayed phase of ischemic brain injury. Nat Med. 2009:15:946-50.

241. Luo Y, Zhou Y, Xiao W, Liang Z, Dai J, Weng X, Wu X. Interleukin-33 ameliorates ischemic brain injury in experimental stroke through promoting Th2 response and suppressing Th17 response. Brain Res. 2015;1597:86-94

242. Guo Y, Chen X, Li D, Liu H, Ding Y, Han R, Shi Y, Ma X. PR-957 mediates neuroprotection by inhibiting Th17 differentiation and modulating cytokine production in a mouse model of ischaemic stroke. Clin Exp Immunol. 2018; 193:194-206.

243. Stubbe T, Ebner F, Richter D, Engel O, Klehmet J, Royl G, Meisel A, Nitsch R, Meisel C, Brandt C. Regulatory T cells accumulate and proliferate in the ischemic hemisphere for up to 30 days after MCAO. J Cereb Blood Flow Metab. 2013;33:37-47.

244. Kleinschnitz C, Kraft P, Dreykluft A, Hagedorn I, Gobel K, Schuhmann MK, Langhauser F, Helluy X, Schwarz T, Bittner S, et al. Regulatory T cells are strong promoters of acute ischemic stroke in mice by inducing dysfunction of the cerebral microvasculature. Blood. 2013;121:679-91.

245. Liesz A, Suri-Payer E, Veltkamp C, Doerr H, Sommer C, Rivest S, Giese T, Veltkamp R. Regulatory $T$ cells are key cerebroprotective immunomodulators in acute experimental stroke. Nat Med. 2009;15:192-9.

246. Urra X, Cervera A, Villamor N, Planas AM, Chamorro A. Harms and benefits of lymphocyte subpopulations in patients with acute stroke. Neuroscience. 2009;158:1174-83

247. Gong N, Liu J, Reynolds AD, Gorantla S, Mosley RL, Gendelman HE. Brain ingress of regulatory T cells in a murine model of HIV-1 encephalitis. J Neuroimmunol. 2011;230:33-41.

248. Huang X, Stone DK, Yu F, Zeng Y, Gendelman HE. Functional proteomic analysis for regulatory $T$ cell surveillance of the HIV-1-infected macrophage. J Proteome Res. 2010;9:6759-73.

249. Moreno-Fernandez ME, Rueda CM, Rusie LK, Chougnet CA. Regulatory T cells control HIV replication in activated T cells through a cAMP-dependent mechanism. Blood. 2011;117:5372-80.

250. Kinter A, McNally J, Riggin L, Jackson R, Roby G, Fauci AS. Suppression of HIV-specific T cell activity by lymph node CD25+ regulatory T cells from HIV-infected individuals. Proc Natl Acad Sci U S A. 2007:104:3390-5. 
251. Kessler PA. Potential Role of Regulatory T Cells in Mother-to-Child Transmission of HIV. Curr HIV Res. 2018;16:396-403.

252. Group I-ES, Committee SS, Abrams D, Levy Y, Losso MH, Babiker A, Collins G, Cooper DA, Darbyshire J, Emery S, et al. Interleukin-2 therapy in patients with HIV infection. N Engl J Med. 2009;361:1548-59.

253. Weiss L, Letimier FA, Carriere M, Maiella S, Donkova-Petrini V, Targat B, Benecke A, Rogge L, Levy Y. In vivo expansion of naive and activated CD4+ CD25+FOXP3+ regulatory T cell populations in interleukin-2-treated HIV patients. Proc Natl Acad Sci U S A. 2010;107:10632-7.

254. Moreno-Fernandez ME, Zapata W, Blackard JT, Franchini G, Chougnet CA. Human regulatory $T$ cells are targets for human immunodeficiency Virus (HIV) infection, and their susceptibility differs depending on the HIV type 1 strain. J Virol. 2009;83:12925-33.

255. Weiss L, Piketty C, Assoumou L, Didier C, Caccavelli L, Donkova-Petrini V, Levy Y, Girard PM, Burgard M, Viard JP, et al. Relationship between regulatory $T$ cells and immune activation in human immunodeficiency virus-infected patients interrupting antiretroviral therapy. PLoS One. 2010;5: e11659.

256. Li G, Nunoya Jl, Cheng L, Reszka-Blanco N, Tsao LC, Jeffrey J, Su L. Regulatory T Cells Contribute to HIV-1 Reservoir Persistence in CD4+ T Cells Through Cyclic Adenosine Monophosphate-Dependent Mechanisms in Humanized Mice In Vivo. J Infect Dis. 2017;216:1579-91.

257. Jiao YM, Liu CE, Luo L, Zhu WJ, Zhang T, Zhang LG, Su LS, Li HJ, Wu H. CD4+CD25+CD127 regulatory cells play multiple roles in maintaining HIV-1 p24 production in patients on long-term treatment: HIV-1 p24-producing cells and suppression of anti-HIV immunity. Int J Infect Dis. 2015:37:42-9.

258. Tran TA, de Goer de Herve MG, Hendel-Chavez H, Dembele B, Le Nevot E, Abbed K, Pallier C, Goujard C, Gasnault J, Delfraissy JF, et al. Resting regulatory CD4 T cells: a site of HIV persistence in patients on long-term effective antiretroviral therapy. PLoS One. 2008;3:e3305.

259. Mathews S, Branch Woods A, Katano I, Makarov E, Thomas MB, Gendelman HE, Poluektova LY, Ito M, Gorantla S. Human Interleukin-34 facilitates microglia-like cell differentiation and persistent HIV-1 infection in humanized mice. Mol Neurodegener. 2019;14:12.

\section{Publisher's Note}

Springer Nature remains neutral with regard to jurisdictional claims in published maps and institutional affiliations.

Ready to submit your research? Choose BMC and benefit from:

- fast, convenient online submission

- thorough peer review by experienced researchers in your field

- rapid publication on acceptance

- support for research data, including large and complex data types

- gold Open Access which fosters wider collaboration and increased citations

- maximum visibility for your research: over $100 \mathrm{M}$ website views per year

At BMC, research is always in progress.

Learn more biomedcentral.com/submissions 